\title{
Nutritional biomarkers: current view and future perspectives
}

Shubhra Pande ${ }^{1}$, Valentina A. Kratasyuk ${ }^{1 \#}$, Nadezhda N. Medvedeva ${ }^{2}$, Oxana A. Kolenchukova ${ }^{1,2}$, Alla B. Salmina ${ }^{2 *}$

${ }^{1}$ Post doctoral Fellow, Laboratory of Bioluminescent Biotechnologies, Department of Biophysics, Institute of Fundamental Biology and Biotechnology, Siberian Federal University; Researcher, Research Institute of Molecular Medicine and Pathobiochemistry, Krasnoyarsk State Medical University named after Prof. V.F. Voino-Yasenetsky, Krasnoyarsk, Russia

${ }^{1 \#}$ Head of the Department of Biophysics, Institute of Fundamental Biology and Biotechnology, Siberian Federal University; Institute of Biophysics, Siberian Branch of RAS, Krasnoyarsk, Russia

${ }^{2}$ Head of the Department of Human Anatomy and Histology, Krasnoyarsk State Medical University named after Prof. V.F. Voino-Yasenetsky, Krasnoyarsk, Russia

2* Head of the Department of Biochemistry, Medical, Pharmaceutical \& Toxicological Chemistry, Krasnoyarsk State Medical University named after Prof. V.F. Voino-Yasenetsky, Krasnoyarsk, Russia

${ }^{1,2}$ Associate Professor, Leading Researcher, Federal State Budgetary Scientific Institution «Scientific Research Institute of medical problems of the North», Professor of the Department of Biophysics, Institute of Fundamental Biology and Biotechnology Siberian Federal University, Krasnoyarsk, Russia

*Corresponding Author: Prof. Valentina A. Kratasyuk 
Address: Head of the Department of Biophysics, Institute of Fundamental Biology and Biotechnology, Siberian Federal University; Institute of Biophysics, Siberian Branch of RAS, Krasnoyarsk, Russia

Email- valkrat@mail.ru

Telephone- +79676085643 


\title{
Nutritional biomarkers: current view and future perspectives
}

\author{
Shubhra Pande 1, Valentina A. Kratasyuk 1*, Nadezhda N. Medvedeva 2, Oxana A. Kolenchukova \\ 1, Alla B. Salmina 2
}

\begin{abstract}
There is a poor relationship between nutrient intake and existing nutritional biomarkers due to variety of factors affecting their sensitivity and specificity. To explore the impact of nutrients at molecular level and devising a sensitive biomarker, proteomics is a central technology with sirtuins as one of the most promising nutritional biomarker. Sirtuins (seven mammalian sirtuins reported so far), have been reported to perform protein deacetylases and ADP-ribosyltransferases activity. It is distributed in different cellular compartments thereby controlling several metabolic processes. Sirtuins are NAD + dependent which implicates a direct effect of the metabolic state of the cell on its activity. Calorie restriction upregulates the mammalian sirtuin protein levels in variety of tissues and organs where it acts upon both histone and nonhistone substrates. Sirtuin senses nutrient availability and impacts gluconeogenesis, glycolysis and insulin sensitivity. It deacetylates and inhibits the nuclear receptor that activates fat synthesis and adipogenesis in the body, leading to fat loss and bringing favorable cellular and health changes. Sirtuins mediates intracellular response that promotes cell survival, DNA damage repair thereby increasing the cell longitivity. The activation of sirtuins brings a wide spectrum of other health benefits and its activity levels are indicative of nutritional status as well as disease progression in cancer, inflammation, obesity, cardiovascular diseases, and viral infections. There are several foods that activate sirtuin activity and offer significant health benefits by their consumption.
\end{abstract}

Key words- Sirtuins, NAD+, biomarker, proteomics, calorie restriction, longitivity 


\section{Introduction}

Nutritional epidemiology depends on accurate dietary information so as to investigate associations between diet and disease. Most popular dietary assessment tool is self-reporting through questionnaire which is highly subjective and prone to bias in form of over or under reporting. Biological markers (biomarkers) on the other hand are objective, unbiased, overcome intra individual diet variability (Hedrick et al., 2012) and helps to obtain a more proximal and integrated assessment of nutrient status (Potischman, 2003). Hulka (1993) has defined biomarker as "cellular, biochemical or molecular alteration that is measurable in biological media such as human tissues, cells, or fluids." Biomarkers can be understood as surrogate endpoints in clinical studies that may be used to predict future events. Nutritional biomarkers are indicators of dietary exposure and indicate past dietary intakes. The main reasons for using biomarkers are to achieve higher precision over memory based dietary assessment (Kaaks et al., 1997) because they are standardized in clinical and laboratory practices (Don and Kaysen, 2004). They are of two main classes: recovery biomarkers (based on the total excretion of the marker over a defined time period as urinary nitrogen and potassium) and concentration biomarkers (based solely on the concentration of the respective marker; with no knowledge or details about the physiological balance of intake and excretion) (Combs et al., 2013; Kuhnle, 2012). Nutritional research has established several biomarkers for nutrients and food items as indicated in Table-1.

Determination of the human nutritional status is an important component to understand the physiologic health of a person (Alp Ikizler, 2012) . An exemplary nutritional marker should quickly acknowledge the variations caused owing to consumption of nutrients, be unaffected by presence of other diseases, must be easily and accurately tested with easily available equipment in the hospitals, and should be affordable for the patients. Further, the biomarker must have the attributes as short biological half-life, occur in a proportionately tiny pool, have a catabolic rate which can be foreseen, 
and should be sensitive to specific nutrient intake. The present review is dedicated to identify, explore and establish sirtuin, a NAD + dependent deacetylase, as a promising sensitive and specific proteomic biomarker for determining the human nutritional status.

\section{Popular nutritional biomarkers}

We begin with a bird's eye view on the popular nutritional biomarkers and discussing their degree of suitability to ascertain nutritional status. In the past, the circulating concentration of albumin had been the most accepted nutritional biomarker and was considered as the most trusted agent to reveal the nutritional status of a person. However, they are predominantly unresponsive to changes in nutrient ingested, due to comparably vast body pool, which may require a fortnight to return to normal levels if the pool has been affected (Spiekerman, 1995). It has a long half-life (20 days) and is influenced by patient's hydration status and consequently the renal functions (Beck and Rosenthal, 2002). Besides, serum albumin levels are not a good choice of biomarker for elderly. In geriatric population, even without any inflammation, the albumin levels are reported to be elevated (Kuzuya et al., 2007). Also certain physiological stresses exerted during dehydration, marasmus, blood transfusions, liver failure, instances of inflammation, infection or metabolic stress, nephrotic syndrome, burns and trauma etc. has been observed to influence the circulating levels of serum albumin (Spikerman, 1995; Banh, 2006).

Transthyretin was later termed as prealbumin (or thyroxine-binding prealbumin) since it moved more rapidly than albumin on electrophoresis. It is a circulating transport protein also reported in cerebrospinal fluid. It carries thyroxine (T4) hormone and retinol-binding protein conjugated with retinol. Serum prealbumin has been reported to have a shorter half-life ( 2.5 days) than albumin but the levels of prealbumin increases with severe renal failure and consumption of corticosteroids and oral contraceptives. The serum concentration of prealbumin depletes with liver disease, hepatitis, dialysis, 
hyperthyroidism, pregnancy, hyperglycemia and inflammation. In the inflammatory state, its synthesis lowered being a negative acute-phase protein (Gibson, 2005), thus we understand the relative insensitivity of prealbumin as a nutritional biomarker.

Banh (2006) observed that C-reactive protein (CRP) is a comparatively rapid marker (halflife-19 hours) in comparison with previously discussed biomarkers namely albumin and prealbumin. It is a choicest biomarker for inflammation. CRP substantiates the reliability of prealbumin marker and generally is used along with prealbumin. Even though CRP is significantly sensitive to inflammations, there is a considerable inter-individual variability which is highly undesirable. Its concentration (normal value- $10 \mathrm{mg} / \mathrm{L}$ ) in healthy adults, may rise up to a 1000 -fold in response to an inflammatory stimulus and the degree of increase varies from patient to patient. This variability may be detrimental to the diagnostic reliability of CRP (Reny et al., 2002). Other factors as low grade inflammatory processes, dietary and behavioral influences and cardiovascular and non-cardiovascular medical conditions are associated with an increase in CRP levels. The concurrent use of CRP as a promising nutritional indicator has also not been substantiated.

Transferrin and retinol binding protein have also been identified as biomarkers of nutritional status. Transferrin has a long biological half-life (8-10 days) while retinol binding protein has a significantly short half-life (12 hours). Transferrin is involved in iron transport and its levels are influenced by existing iron status. Thus, iron deficiency may trigger rise in transferrin levels resulting in increased iron absorption and therefore, it is often used as an indirect method for determining total iron binding capacity. Hence this biomarker is greatly affected by intrinsic iron levels. Retinol binding protein levels are dependent on the concentration of Vitamin A and zinc. Low levels of these two nutrients inhibit mobilization of retinol binding protein in the liver. In the state of kidney failure owing to significant elevation of these two nutrients, the reliability and sensitivity of this marker is greatly lost (Gibson, 2005). 
We can now conclude that there is a poor relationship between serum protein levels and nutrition status. Poor intake of nutrients does not consistently correlate with decrease in biomarkers as albumin, prealbumin, transferrin, and retinol binding proteins. Also, an increasing intake necessarily does not increase their levels. In light of these disparate results, it would be apt to conclude that serum proteins are neither specific, nor sensitive indicators of nutritional status. As negative acute-phase reactants, the concentrations of these proteins are affected by the acute phase response (during inflammation) and have been shown to be inversely associated with CRP. Many other extrinsic and intrinsic factors also affect the concentration of these proteins. Therefore, there exists the dearth of a nutritional biomarker that is specific, sensitive and unaffected by other disease conditions.

\section{Proteomic biomarkers}

Every nutritional process depends on the interplay of a very large number of proteins that are expressed at the level of the cell, organ or the whole organism. The potential importance of proteomics for the nutritional sciences has been well recognized and accepted. Dietary prevention/management of diseases, biomarkers and individualized requirements of nutrients are the most recent, yet very crucial dimension that explains role of proteomics in nutritional sciences (Wang et al., 2006). A proteomic biomarker is defined as a specific peptide or protein associated with a specific condition, such as the onset, manifestation, or progression of a disease or a response to the treatment (Mischak et al., 2010). It is well established that proteomics can be used to identify the entire protein complement of a cell, tissue, or microorganism at different stages of growth and development, as well as to examine the integrated response to a particular intrinsic (hormonal, nutritional) or extrinsic (environmental) challenge. Thus, we propose that one of the major applications of proteomics may lie in the identification of degenerative disorders at the protein level, during very early stage of disease initiation (Andersen et al., 1997; Trayhurn P, 2000; Fuchs et al., 2005). 
The utilization of proteomics in nutritional research includes comprises of dimensions that identifies the composition and characteristics of proteins ingested, that is further detailed by digestion and absorption of nutrients in the gastrointestinal tract. Advanced proteomics research investigates nutrient metabolism (synthesis and catabolism) and regulation, transport of nutrients, tissue-specific metabolism of nutrients, role of phytochemicals in growth, signal transduction, cellular defense against oxidative stress, cell proliferation, differentiation, apoptosis and gene expression in response to nutrients and other dietary factors (which may impact absorption of nutrients in the body) (Wang et al., 2006). The application of proteomics requires access to specialized equipment and skills and expertise to operate it. Proteomics has the advantage over cDNA micro-arrays of quantifying the functional product (protein) of the gene expression, and allows identification of certain modifications that may relate to the activation or inactivation of proteins by dietary interventions. Such circulating proteins play a major physiological role in target organs, and also successfully reflect the changes in mechanisms initiated by dietary changes (de Roos and McArdle, 2008). The classical two-dimensional (2D) gel electrophoresis coupled with spot analysis by mass spectrometry, is still one of the most widely used proteomic technique utilized to identify changes in the individual proteins of tissues, cells and bio-fluids due to dietary changes (Fuchs, 2005). This approach not only identifies individual proteins but also reveals the rate of metabolic turnover. However it is not reliable technique to visualize and detect differential regulation of low concentration proteins. Also, very hydrophobic, acidic or basic proteins cannot be accurately detected by this method (Gygi et al., 2000). Moreover, this method is labour intensive (de Roos and McArdle, 2008) and significantly uneconomical. Therefore, 2D gel electrophoresis may not always represent the most sensitive tool to reveal effects of nutritional interventions on inflammatory pathways. 
Nutritional science is at a transactional stage. In past, the nutritional science primarily focused on identification of essential nutrients and understanding their biological importance in maintaining health, but today it significantly focuses at health promotion, disease prevention and performance improvement. This is accomplished by studying the pattern of overall composition of the diet, the levels of specific nutrients and non-nutrient components of foods and many other aspects of lifestyle that affects the flow of genetic information from gene expression to protein synthesis and protein degradation. For the nutritional scientist, this information is of special interest in studying the diseases where diet plays an important role.

Nutritionists generally encounter challenges as they seek to understand the impact of nutrients at the molecular level. As a result there exists a vital scope to establish proteomics in field of nutrition. Proteomics is a central technology in post-genomic nutritional research for assessing the effects of diet composition, specific nutrients and non-nutrient components on the genome and on mammalian metabolism. And if the nutrition science has to match the advances of other branches of biology in the post-genomic era, it must utilize proteomic biomarkers to assess minutest, yet crucial aspects of human nutrition (Fuchs et al., 2005).

Noteworthy are the families of Silent Information Regulators (SIR) that encodes for genes which promote body's defenses during physiological stress like calorie restriction. The genes from this family have been well documented and studied to significantly maintain health and prolong life expectancy in wide variety of organism ranging from bacteria to mammals. Biochemically, SIR2 removes acetyl tags from the histones, but interestingly its enzymatic activity requires oxidized nicotinamide adenine dinucleotide (NAD+). Now NAD + has been already known as a participant and key regulator of many metabolic reactions in cells. Due to an association between SIR2 and NAD+, SIR2 activity modulates multiple biological processes particularly associated with metabolism (metabolic redox reactions), DNA repair etc. Hence this association potentially links the relation 
among diet and several diseases and even ageing. Sirtuins are members of the sirtuin family of proteins, homologs of the Sir2 gene. We will now undertake an in depth understanding designed to point at the potential of sirtuins as an ideal nutritional biomarker.

\section{NAD+-dependent cellular deacetylases as emerging nutritional biomarkers}

Sirtuins has been a subject of considerable interest and excitement as an important biomarker in ageing biology ever since it was discovered in late 1990's. Sirtuins were initially referred to as evolutionarily conserved NAD+ dependent class III histone deacetylases (HDAC) implicated in several age related degenerative diseases such as cancer, diabetes, cardiovascular disease and neurodegenerative disorders (Tao et al., 2010). Consequently, it was observed that, apart from histones, sirtuins also are capable to deacetylate several regulatory protein, structural protein and catalytically active proteins as key substrates, thereby revealing their ability to utilize wide range of substrates (Martínez-Redondo and Vaquero, 2013). They are extensively reported and well established as NAD+ dependent deacetylases/deacylases and ADP-ribosyltransferases, that couple protein deacetylation of histone and non-histone substrates with the energy state of the cell (the cellular NAD+/NADH ratio) (Schwer and Verdin, 2008). This yields a highly regulated proteome with more than 4000 acetylated proteins in the tissues of experimental rats (Lundby and Olsen, 2012) (Fig- 1).

It has been scientifically proven that nearly all enzymes of glycolysis, gluconeogenesis, glycogen metabolism, fatty acid oxidation, nitrogen metabolism, tricarboxylic acid (TCA) cycle, and oxidative phosphorylation are abundantly acetylated (Zhao et al., 2010) along with the frequent conservation of acetylation sites across diverse organisms (Choudhary et al., 2014). Several published reports have indicated that sirtuins are virtually ubiquitous throughout the kingdoms of life. It is reported to be present from bacteria to eukaryotes. The first NAD+ 
dependent deacetylases namely SIRT2 was reported in the budding yeast (Saccharomyces cerevisiae) (Frey, 1999; Frey, 2000; Greiss and Gartner 2009). So far seven mammalian sirtuins have been identified and their distribution is throughout the cellular compartments. This explains the diversity and complexity in their cellular localization and functions (Fyre, 2000; Moris, 2013). Substantial evidences on association between sirtuins and disease conditions such as diabetes, metabolic diseases, cardiovascular diseases, neurodegenerative diseases and cancers have been reported in mostly animal models (Haigis and Sinclair, 2010; Guarente, 2014). The composite families of sirtuins contain approximately 260 amino acids which have a high degree of sequence similarity. This family has been further divided and categorized into five different classes namely I, II, III, IV and U. The division based of phylogenetic analysis of more than sixty sirtuins which were obtained from variety of organisms. The human genome encodes seven sirtuins which are categorized in the classes from I to IV; while the U-class sirtuins are reported only in Gram-positive bacteria (North et al., 2003).

Michishita et al. (2005a) has documented that all the known seven mammalian sirtuins (SIRT1-7) show dynamic intracellular localization and deacetylate different sets of substrate proteins. Michan and Sinclair (2007) and Zhang and Kraus (2010) observed that SIRT1 positions in the nucleus (Euchromatin) and regulates metabolic processes of transcription factors such as p53 and PGC-1 $\alpha$. North et al. (2003) reported that location of SIRT2 is mainly in the cytosol where it deacetylates $\alpha$ - tubulin. The biological activities of SIRT1 and SIRT2 have been most extensively studied due to the enormous significant metabolic activities attributed to both of these (Li and Kazgan, 2011). The mitochondria are reported to contain SIRT3, SIRT4, and SIRT5 (Girtz and Steegborn, 2010). SIRT 6 occurs in heterochromatin and deacetylates histones and regulates DNA stability and repair (Michishita et al., 2005 b; Kaidi, 2010). SIRT3 regulates a large set of metabolic enzymes while SIRT6 and SIRT7 are nuclear isoforms. SIRT7 has been 
reported to monitor the activity of RNA polymerase (Ford et al., 2006) and to deacetylate p53 (Vakhrusheva et al., 2008), thereby exhibiting a crucial role in various types of cancers and identifying SIRT7 as one of the promising cancer drug targets (Priyanka et al., 2016).

SIRT1 has a decisive role in glucose homeostasis and lipid metabolism in various tissues as adipose, liver, pancreas, and skeletal muscle (Kume et al., 2010). Manifold studies have reported that SIRT1 and SIRT3 share the common attribute of significant tumor suppression activity (Bell et al., 2011; Finley et al., 2011; Herranz et al., 2010; Herranz and Serrano, 2013). SIRT4 is the only mammalian sirtuin without a reported deacetylation substrate. Instead of deacetylation SIRT4 performs ADP-ribosylation, which is a second type of reaction that can be catalyzed by sirtuins through utilizing glutamate dehydrogenase (Haigis et al., 2006). There is only one physiological substrate known for SIRT5, namely- carbamoylphosphate synthetase I (Hirschey et al., 2011) (Table- 2).

With such reports, there is a spontaneous central question that can sirtuins promote health against ageing associated diseases? Are these proteins important for mediating anti-ageing effects of a low-calorie diet? How calorie restriction impacts their activity? Do they have any role in expanding life span of organisms? And most importantly how can sirtuin be an appropriate nutritional biomarker? In the following section, we will explore role of sirtuin in metabolism to address the questions raised above.

\section{Role of sirtuin in metabolism}

Sirtuins are major regulators of a variety of cellular processes, ranging from energy metabolism, stress response, tumorigenesis and ageing. Hagis and Sinclair (2010) have reported that SIRT1 is involved in hepatic gluconeogenesis, fat mobilization, and pancreatic insulin secretion. It also regulates hepatic fatty acid oxidation. The activity of sirtuin is influenced by availability of 
nutrients which is expressed as obesity-induced inflammation in macrophages and modulation of activity of the circadian clock in metabolically active tissues. During fasting or calorie restriction, there is negative energy balance and SIRT1 has been reported to be upregulated. It stimulates gluconeogenesis and inhibits glycolysis (Nemoto et al., 2004; Nie et al., 2009; Rodgers et al., 2005; Rodgers and Puigserver, 2007). In a cell, gluconeogenesis and glycolysis are highly coordinated and well-regulated pathways. If one pathway is relatively inactive the other becomes active. Now both glycolysis and gluconeogenesis are significantly exergonic under cellular conditions and there is no thermodynamic barrier to regulate these two simultaneous activities. It is by the regulated activity of distinctive enzymes for each pathway, that the two processes are controlled, resulting in only one pathway being activated at a given time. Rodgers et al. (2005) experimented that sirtuin promotes this reciprocal regulation of the two pathways during negative energy balance through deacetylation of PGC-1 $\alpha$, the transcriptional coactivator. It was also reported that SIRT1 deacetylates PGC-1 $\alpha$ in a NAD+ dependent manner (Picard et al., 2004; Nemoto et al., 2005; Rodgers et al., 2005; Liu et al., 2012). Importantly, the SIRT1 mediated regulation of PGC-1 $\alpha$ was found to be essential during fasting or pyruvate-mediated increases in gluconeogenic genes (PEPCK and G6Pase) and glucose output in cultured hepatocytes. Furthermore, this deacetylation also acts to decrease the expression of glycolytic genes (glucokinase and LPK) (Rodgers et al., 2005).

This stimulating effect of SIRT1 on hepatic glucose output during fasting was also confirmed in mice (Rodgers and Puigserver, 2007; Erion et al., 2009). This finding signifies the putative role of sirtuin as a marker of an important nutritional aspect namely hepatic glucose levels.

SIRT1 may also act to regulate the hepatic glucose production during prolonged fasting (Liu et al., 2012). Further, during negative energy balance, the liver mobilizes lipid and glycogen stores into energy by $\beta$-oxidation of fatty acid and glycogenolysis or gluconeogenesis. Now SIRT1 inhibits the early phase of glucogenogenesis by regulating the key mediator during short-term fasting (Li, 
2008). This implies that during negative energy balance, there is enhanced SIRT1 deacetylation coupled with activation of PGC-1 $\alpha$ along with the enhanced lipid catabolism. The consequence is significantly improved fatty acid oxidation and enhanced glucose homeostasis (Purushottam et al., 2009; Dominy et al., 2010). Alternatively, in the well fed state, when there is positive energy balance, the metabolic machinery aims towards storage of energy in form of glycogen in the liver. Thus, the overall influence of SIRT1 on the regulation of gluconeogenesis is decided by the complex multiple interactions among factors of different phases of negative or positive energy balance (Li, 2013). Liu et al., (2012) has verified that as a result of increased NAD+ during glycolysis, there is SIRT1 mediated repressing of PPAR $\gamma$ a (transcription factor that regulates genes of fat storage) and activation of PPARGC1B (transcription factor for mitochondrial biogenesis that increases oxidative metabolism) leading to the metabolic transition from glycolysis to fatty acid oxidation (Fig- 2). The above studies help us understand the intricate and highly dependent intercellular interactions of transcription factors with SIRT1 that unanimously aim towards shift of the metabolic process based upon the energy state of the cell.

New age scientific developments in agriculture and technologies with blooming food processing industries have promoted the intake of rich high-calorie diets and a sedentary lifestyle. This leads to obesity, cardiovascular disorders, diabetes etc. In the obese individuals, excess adipose tissue increases the levels of Nonestrified fatty acids (NEFA). These excess NEFA accumulates on other metabolic tissues such as liver, muscle, and pancreatic $\beta$-cells, resulting in atherogenic dyslipidemia, insulin resistance, and hyperinsulinemia (Schug et al., 2010; Schug and Li, 2011). Tarantino et al., (2014) have reported that in obese subjects (Body Mass Index above 30), a lowered serum levels of SIRT4 was reported, indicative of inverse relationship between Body Mass Index and circulating SIRT4. This observation has been established as a putative cause of risk factors for coronary artery diseases such as low HDL, visceral obesity expressed as high weight/height ratio. 
SIRT1 influences hepatic cholesterol and bile acid homeostasis. It operates by affecting the nuclear receptors present in liver. Farnesoid X receptor (FXR) is the bile sensor which is targeted by hepatic SIRT1 during the process of metabolic regulation (Purushottam et al., 2012). The signaling pathway of SIRT1 and FXR mutually interacts and influences metabolism at multiple levels. As a result, these two regulates the homeostasis between hepatic bile acid and cholesterol mobilization in the body. Also, SIRT1 is supposed to regulate hepatic lipid metabolism through deacetylation of the sterol regulatory element-binding protein (SREBP) (Ponugoti et al., 2010; Walker et al., 2010). To unwind this mechanism, it must be highlighted that fasting (short-term food deprivation) produces an instant metabolic drift from synthesis of lipids and cholesterol to their mobilization. When intracellular lipids and cholesterol levels are high, SREBP precursors are tethered and restricted and their gene transcription is activated during depletion of lipids and cholesterol (Osborne and Espenshade 2009; Riu, 2014). Now these negative feedback mechanisms control the processing of the precursor forms of SREBP but question is as to how SREBP are controlled by nutrient deprivation? There are no reports as to how nutrient deprivation triggers the SREBP family member affecting the transcription in response to insulin signaling (Walker et al., 2010)? One attractive and suitable candidate to initiate deacetylation of the SREBP family of transcription factors in response to nutrient deprivation is SIRT1 (Guarente, 2006), as SREBP proteins are required for cholesterol and fatty acid biosynthesis. SIRT1 can directly deacetylate SREBP thereby contributing to its metabolic regulation. It may be claimed that SIRT1 helps to improve insulin sensitivity in obese subjects by offering a protective effect against obesity. The concept that activation of SIRT1 can result in loss of body fat without affecting the caloric intake (Baur et al., 2006) could open the door for novel treatment for obesity and related diseases (Fig-3). Further, sirtuin may be believed as a promising biomarker to reveal the nutritional status in terms of fat accumulation and oxidation and its modulation will beneficially impact the storage and metabolism of fat in the body. 
The effect of sirtuin on overall metabolism is multidimensional and its metabolic functions reveal that their effect on degenerative diseases is extremely crucial. Sirtuins influence the immune system also by reducing inflammation in multiple tissues particularly macrophage (Schug et al., 2010), while the reduction of SIRT1 in hepatic cells caused in increased local inflammation (Purushotham et al., 2009). Baur et al. (2006) revealed that a mice fed a high-fat diet when administered with SIRT1, resulted in improved liver functions and metabolism. In a hyperglycemic environment, SIRT1-mediated activation prevents lipid accumulation (Hou et al., 2008). In fact in the brain, SIRT1 functions as a potential link between the pituitary hormones and calorie restriction longevity pathways in mammals (Cohen et al., 2009). Many changes induced by SIRT1 activation are related to increased mitochondrial metabolism and antioxidant protection in the fasting fish (Simó-Mirabet et al., 2016). It is worth noting that SIRT1 overexpression downregulated the proinflammatory genes in mice (Pfluger et al., 2008; Yoshizaki et al., 2010), while obesity with chronic inflammation was associated with reduced levels of SIRT1 (Vachharajani et al., 2016). This finding advocates and highlights the capability of sirtuin as a biomarker for lipid accumulation led inflammations in biological systems.

The members of sirtuin families being NAD + dependent deacetylases, participate in many cellular processes as cell proliferation, senescence and stress response. They might play either a promoting or suppressing role, depending on the organ or even the species. Expression of SIRT1 increases in prostate cancer (Hauffman et al., 2007) and acute myelocytic leukemia (Bradbury et al., 2005). An enhanced overexpression of SIRT1 in colonic tubular adenoma was observed and it was advocated as a useful biomarker in the diagnosis of high grade dysplasia and invasive carcinoma (Zhang and Wang, 2013). Aligning with them is the finding of Grbesa et al. (2015), who observed that the activity of SIRT1 and SIRT2 protein was significantly increased in the cancer cell lines of lungs as compared with non-tumor epithelial cells of the lungs. The expression of SIRT1 and SIRT2 
proteins was also found to increase in tumor cells of lungs than normal lung cells. These findings even suggested that SIRT1 inhibitors may act as potential anti-cancer agents and that the potential tumor suppressive effects of SIRT1 need to be kept in mind while considering SIRT1 inhibitors for cancer treatment (Li et al., 2008).

There are multiple studies that demonstrated that the possible regulatory mechanism of SIRT1 on the cancer gene is associated with tumor protein p53 (Hishida et al., 2012). As we already know that the p53 protein is a tumor suppressor protein. Its lowered expression or mutation leads to enhanced risk of cancer (Muller and Vousden, 2013). Deacetylation of p53 by SIRT1 is reported to play an important role in preventing p53 activation and thus promoting cancer cells (Brooks and Gu, 2010; Castro et al., 2013). This is how SIRT1 impacts the activity of p53 gene and gets highlighted as a cancer promoting agent. But there is a considerable paradox in this regard.

Several contradicting studies have indicated that the p53 inactivation by SIRT1 actually promotes cell survival during stress (Luo et al., 2001) and that SIRT1 arrests p53 induced apoptosis by p53 deacetylation and induction of manganese superoxide dismutase (MnSOD) (Tanno et al., 2010; Tao et al., 2010). We need more research and insight to simplify exact reason and role of increased SIRT1 status during cancer. Despite clear inhibitory effect of increased SIRT1 expression on tumor suppressors like p53, other studies have suggested that SIRT1 may have tumor suppressive functions as well. This can be partly explained by studies conducted by (Maiese et al., 2009) where they observed that SIRT1 offers protection against oxidative stress through modulation of forkhead transcription factors in some cells. While Hasegawa et al., (2008) observed that SIRT1 protects cells against oxidative stress by increasing the activity of antioxidant enzyme- catalase. The calorie restriction helps to combat oxidative stress through SIRT3-mediated enhancement of Super Oxide Dismutase (SOD) activity (Qui et al., 2010). Also, SIRT1 overexpression increases the tolerance against free radical toxicity in neuronal cells (Chong and Maiese, 2008). Howitz et al. (2003) 
studied about resveratrol which was reported to improve chances of cell survival by stimulating SIRT1- dependent deacetylation of p53.

The expression and activation of SIRT1 can be influenced by several cellular conditions such as calorie restriction, exercise and oxidative stress in the cell. SIRT1 uses NAD+ as a substrate, but the level of NAD+ can also control the deacetylating activity of SIRT1. Moreover, the activity of SIRT1 may depend on the cell process and cell type studied. So can it be justified to propose that sirtuin levels increases during cancer as a part of body's homeostasis and performs protective mechanism to fight against cancer and induce longitivity as sirtuins are genes for longitivity? This aspect of research is scattered with contradictions and bidirectional views, therefore it needs more focus and insight to actualize the role of sirtuin in cancers.

SIRT4 has been observed to modulate the metabolism of NEFA. The adipose tissues release NEFA, triggering oxidative stress that results in endothelial dysfunction, early atherosclerosis, culminating to risk factors of coronary artery disease (Tarantino et al., 2014). Lowering activity of SIRT4 has been associated with an increased free fatty acid oxidation in liver and in muscle (Nasrin et al., 2010). This finding indicates that an enhanced level of SIRT4 may qualify as an indicator of better antioxidant status of the organism in terms of concentration of NEFA. (Wang et al., 2007) and Calabrese et al. (2012) reported that sirtuin reduce the reactive oxygen species (ROS) by modulating the acetylation of the respiratory chain, stimulating mitochondrial SOD and isocitric dehydrogenase which generates NADPH for glutathione pathway. Such reports establish the significant antioxidant potential of sirtuins. Research has also shown that SIRT5 plays a pivotal role in ammonia detoxification (Nakagawa et al., 2009). (Michishita et al., 2008) had observed that all the seven sirtuins are found in detectable limits in all human tissues, moreover the impact of sirtuin on most of the tissues is traceable so we must ascertain the metabolomics performed by sirtuins and examine it in detail. 


\section{NAD+ metabolism and sirtuins}

There is widespread interest in pharmacological manipulation of NAD+ because of their evident role in health and disease (Wang et al., 2015). NAD+ is synthesized from vitamin B3 precursors, mainly nicotinamide in human beings. Biochemically, nicotinamide is also the final degradation product of entire NAD + dependent signaling reactions. This synthesis requires the enzyme nicotinamide phosphoribosyltransferase (NAMPT), which produces nicotinamide mononucleotide (NMN) from nicotinamide (NAM). NMN is then converted directly to NAD+ by the enzyme nicotinamide mononucleotide adenylyltransferase (NMAT). In our body, NAD+ mediated signaling processes affect the control of fundamental cellular events wherein it is an essential redox carrier.

$\mathrm{NAD}+$ dependent deacetylation by sirtuins is observed to affect the activity of proteins along with its stabilization. This in turn regulates physiological process as ageing, transcription, apoptosis, genome stability, mitochondrial biogenesis etc. This shows how sirtuin influences many vital processes in the body. As sirtuins utilizes NAD + as a co-substrate, their activity must depend on the bioenergetic state of the cell (which is, in part, reflected by the NAD+/ NADH ratio and the overall NAD + concentration). It implies that sirtuins directly link the metabolic state with signaling processes. Further they also regulate the cellular response as per the energy state of the cell and associated environmental signals influencing it.

Besides deacetylase activity, sirtuins also perform other enzymatic activities such as ADP ribosylation (SIRT1, SIRT4, and SIRT6), desuccinylation and demalonylation (SIRT5), 
delipoylation (SIRT4), demyristoylation and depalmitoylation (SIRT6) (Martinez-Redondo and Vaquero, 2013). With this diverse spectrum of activities and localizations, it will be wise and apt to label sirtuins as core regulators of transcription and metabolism.

As an agent of ADP-ribosylation, sirtuin mediates transfer of a single (mono-ADPribosylation) or several (polyADP-ribosylation) ADP-ribose units from NAD+ to specific amino acids of acceptor proteins. SIRT4 and SIRT6 are able to mono-ADP-ribosylate proteins (Mao et al., 2011). Intracellular mono and poly ADP-ribosylation is involved in many essential cellular processes viz. DNA repair, apoptosis, transcription, cell cycle progression, energy metabolism and many others (Nikiforov et al., 2015). A recent metabolomics study by (Sadhukhan et al., 2016) indicated that different tissues have very different acyl-CoA profiles and succinylation of protein lysine across different tissues was studied. The research findings suggested that succinylation of lysine predominantly accumulates in the heart when SIRT5 is deleted. ECHA (desuccinylation substrate of SIRT5) is activated by SIRT5 as a result, SIRT5 deficient mice exhibited defective fatty acid metabolism and decreased ATP production, thus implying a reduced cardiac function. Thus, protein succinylation and SIRT5 noticeably exert an important role in cardiac function and heart metabolism. Acetyl-CoA and succinyl-CoA are important intracellular metabolites involved in diverse metabolic pathways including the TCA cycle. The presence of two positively charged amino acids (Tyr102 and Arg105) in the active site of SIRT5 justifies its preference for negatively charged acyl groups such as succinyllysine. Also it has been already documented that SIRT1 is known to affect Ischemic preconditioning (intrinsic process that protects myocardial tissues against ischemic insults) (Hafner, 2010; Nadtochiy et al., 2015; Oellerich and Potente, 2012).

The horizon of SIRT1 removing the acetyl groups from lysine on histones residues, brings into picture the possibility of SIRT1 linkage with viruses. Histones namely- H3K9ac, H3K14ac, or H4K16ac are deacetylated by SIRT1, this in turn triggers the formation of heterochromatin, thereby 
affecting the gene expression (Martinez-Redondoand and Vaquero el, 2013). Sirtuins impacts the result of viral infection by modulating both host and viral gene expression. In turn, viruses manipulate the host epigenetic and transcription machineries by overtaking SIRT1 regulated pathways. This phenomenon is observed in deacetylation of the human immunodeficiency virus (HIV) protein - Tat, thereby enabling HIV transactivation (Pagans et al., 2005). In hepatitis B virus, in the cell lines expressing viral gene products, there is upregulation of SIRT1 mRNA and protein (Ren et al., 2014). The same has been reported in influenza A virus (Koyuncu et al., 2014).

Many deacetylases can influence important transcription factors but it is still ambiguous that whether the impact of sirtuins is redundant or dependent on specific conditions. Also, sirtuins can deacetylate histones on both viral and host chromatin, replicate both DNA and RNA virus, and they exhibit wide diversity of substrates (both histone and nonhistone proteins). Therefore, there is a scope of further research into the understand of mechanisms and explanations as to how both hosts and viruses undergoes clashes to gain control over sirtuin activity to either inhibit or enhance the further viral replication (Budayeva et al., 2016). Interestingly, the bacterial sirtuin (CobB) which is structurally similar to mammalian sirtuins is reported to impact the growth certain bacteriophages (Zhao et al., 2004); so can it be concluded that sirtuins have been the primitive antiviral defense factors that protected against a variety of pathogens? (Koyuncu et al., 2014). How sirtuins link cellular homeostasis to health and to understand the mechanism of action of sirtuin within the cell is the forthcoming concern.

\section{Sirtuins within the cell}

Fyre (2000) has reported that all the seven sirtuins (SIRT1-7) reported in humans are characterized by an evolutionarily conserved sirtuin core domain. This domain has been reported to perform the catalytic activity and reported to contain invariant amino acid residues involved in 
binding NAD+. As mentioned before, sirtuins exhibit NAD+ dependent protein deacetylase activity and ADP ribosyltransferase activity. All sirtuins have been reported to have well defined acetylated substrates except for SIRT4. It is observed that all seven sirtuins target distinct acetylated protein substrates and are localized in distinct sub-cellular compartments. As already mentioned; SIRT1, SIRT6 and SIRT7 occur in the nucleus, SIRT2 is mainly localized in cytosol while SIRT3, SIRT4 and SIRT5 are found in the mitochondria. SIRT1 and SIRT3 have been identified as major regulators of metabolic processes in mammals. They are localized in the nucleus and mitochondria, respectively. SIRT 1 and SIRT 3 deacetylates a variety of proteins and improve cellular energy stores and this is how they contribute in maintaining cellular energy homeostasis (Hirschey et al., 2011; Nogueiras et al., 2012). Localized in mitochondria are SIRT3, SIRT4 and SIRT5, which have been studied and reported as agents who impact the activity of important mitochondrial enzymes and guide the metabolic cycles accordingly to the energy state of the cell (Chalkiadaki and Guarente, 2012). As SIRT1 lacks a DNA-binding domain, it is subjected to target promoters by sequence specific transcription factors so as to incorporate chromatin remodeling and subsequently regulation of gene expression (Prozorovski et al., 2008). Also, SIRT1 is associated with the heterochromatin regions where they promote deacetylation of histone (Vaquero et al., 2004). It can be inferred that owing to multiple molecular functions performed by SIRT1 namely deacetylation, epigenetic modifications, and transcription factor modulation; SIRT1 can be potential link between cellular metabolic status and adaptive transcriptional responses (Bordone and Guarente, 2005).

It is already established that SIRT1 proteins exert their effects through two different pathways namely histone modifications and nonhistone substrates. In histone modification, many ageing related effects are caused by chromatin changes. Since SIRT1 is localised mainly in the nucleus, its physiological actions are partly mediated by its ability to deacetylate nucleosomal histones at specific residues (Pallàs et al., 2008; Miroslava et al., 2014). While the nonhistone 
modification exhibits that once SIRT1 is activated it mediates intracellular responses that promote cell survival, enhance the repair of damaged DNA, and reduce cell division. Experiments indicated that for every acetyl lysine group that is removed, one molecule of NAD + is cleaved, nicotinamide and O-acetyl-ADP-ribose are produced (Harikumar and Aggarwal, 2008; Rauh et al., 2013). Therefore, SIRT1 appears to possess two enzymatic activities; first the deacetylation of a target protein and second the metabolism of NAD + . This distribution helps us to understand the underlying mechanism attributed to sirtuin and its effect on health. In all living organisms, cellular energy is produced and expended using universal "energy currencies" such as ATP and NADH. The tight balance between such anabolic and catabolic pathways ensures that cells do not deplete essential energy stores, which would ultimately cause cellular damage or death. Sirtuins are significantly involved in mammalian energy homeostasis (Nogueiras et al., 2012).

The activity of SIRT1 is highly regulated towards the environmental factors that may influence it. A feeding regime that is reported to accelerate the sirtuin activation is caloric restriction, which corresponds to a lowering of $20 \%-40 \%$ calories below ad libitum intake without inducing malnutrition (Sumeya et al, 2010; Lomb et al., 2010). The levels of sirtuin have been reported to enhance in fasting mice (Kanfi et al., 2008).

Much difference in opinion has been reported in context to understand how calorie restriction can affect the life span (Zhao et al., 2010; Li, 2013). It may be a simple analogy that nutrient shortage leads to increased NAD+ levels, improving sirtuin activity. This shows how calorie restriction improves sirtuin activity. Sirtuins are obviously nutrient sensors as it is actually the nutrient availability which affects the ratio of NADH to NAD+ (Rodgers et al., 2005). Increase in this ratio will automatically increase sirtuins levels. Hagopian et al. (2009) and Gambini et al. (2011) have already established that the calorie restriction results in an increase in [NADH]/ $[\mathrm{NAD}+]$ levels resulting in increased sirtuin levels, thereby impacting the longevity. Laurent et al. 
(2013) gave a concomitant report that genetic and pharmacological restoration of NAD+ levels not only enhances sirtuin activity in experimental animals but consequently delays the ageing process. Hence, there is an opportunity for preventive and/or therapeutic utilization of this mechanism in the improving aspects related to ageing and related disorders. With many favorable physiological and significant health attributes, we must explore and compare various prevailing and potential methods to assay the activities of sirtuins in tissues.

\section{Methods to assess sirtuin activity}

The assay to determine levels/activity of sirtuins has been successfully accomplished by different types of methods. Borra and Denu (2004) have reported that historically the radioactive sirtuin assay uses the radioactive substrates. This technique monitors the transfer of a [3H]-labeled acetyl group from peptide or protein substrate to the [3H] OAADPr product or $[3 \mathrm{H}]$ acetate hydrolyzed from $[3 \mathrm{H}] \mathrm{OAADPr}$. Later, the products and reactants were separated using chromatography, ethyl acetate extraction, or charcoal binding followed by detection under the scintillation counter. Alternatively, release of [14C]-nicotinamide from [14C] NAD + could be estimated by using High Performance Liquid Chromatography (HPLC) or ethyl acetate extraction, or boronic acid resin filtration of the [14C] nicotinamide product followed detection under the scintillation counting (McDonagh et al., 2005). This method is certainly very useful and sensitive, but coupled with drawback of significant health hazards, high cost and cumbersome management of radioactive substrates. One cannot ignore the crucial and sensitive aspect of waste disposal management that is major attribute of radioactive studies.

There is a popular fluorescent assay of sirtuin utilizing fluorescent substrates namely 7 amino 4 methylcoumarin. This substrate conjugates to the C-terminal end of a short acetyl-lysine containing peptide and upon deacetylation causes $\varepsilon$-amino group of the lysine into a trypsin 
substrate. Subsequently, trypsin cleavage releases the fluorophore resulting in an enhanced fluorescence (Wegener et al., 2003). Alternatively, the Cbz-Lys(Ac)-AMC (Z-MAL) substrate can be also employed to asses sirtuin activity by utilizing technique- Fluorescence Resonance Energy Transfer (FRET) (Heltweg, 2003). Here the substrates used are C-terminal fluorophore and an Nterminal quencher (Marcotte et al., 2004), and fluorescence polarization substrates with a C-terminal fluorophore and an N-terminal biotin (Kaeberlein et al., 2005). However, there is some discrepancy in results of SIRT1 activation by some compounds in fluorescent method with the activity measured by non-fluorescent peptides or full length proteins (Borra et al., 2005).

Caliper's mobility shift assay technology (Liu et al., 2008), Enzyme Linked Immunosorbent Assays (ELISA) (Schlicker et al., 2008) and capillary electrophoresis assays (Fan et al., 2009) are other popular methods for sirtuin assay. Each of the above explained assays has its own advantages and disadvantages with noticeable constraints as - unnatural fluorescent, radioactive health hazards, difficult to synthesize substrates, additional enzymatic steps for detection of the deacetylation reaction, specialized equipment, trained technicians to undertake analysis etc. (Schuster et al., 2016).

There exists the possibility of a cutting edge and contemporary bioluminescent system of sirtuin estimation, that hold most promising benefits of being highly quick, safe and sensitive than any other method described above. Moreover, this technique encompasses other techniques due to its application as a miniaturized bio diagnostic and battery operated portable system. The bioluminescent assay is simple, doesn't require any specialized skilled personnel to operate and is capable of conducting high throughput screening of analytes.

To conclude we need a take home message that what are dietary requirements to promote sirtuin activity and what are the future possibilities with sirtuins linked with health. 


\section{Nutrition-affected sirtuin activity}

Hippocrates said few thousand years ago "let food be thy medicine"; and it holds good even today! It is a well-known fact that diet plays a major and key role in maintaining health throughout life. Research has investigated the possibility of consuming specific dietary components that would aid in weight management (Pande and Srinivasan, 2012) and healthy lifespan. Pallauf et al., (2013) have highlighted that certain foods activates sirtuin by mediating calorie restriction like effects in the human body and they are loosely referred to as sirtfoods. These includes mainly the Asian and Mediterranean diets that promotes using turmeric, green tea, extra virgin oil, wild leafy greens, nuts, berries, red wine, dates, herbs etc. Sirtfoods are reported to bring about calorie restriction mediated activation of sirtuin. There arises a spontaneous question that how do they regulate calorie restriction? Do they express calorie restriction like effects or actually help in reducing calorie intake? The answer is both of the above two.

Polyphenols are the common bioactives in green tea, citrus fruits, richly coloured fruits and vegetables, red wines etc. In yeast, resveratrol (active principle of green tea) express calorie restriction by activating sirtuin, thereby improving DNA stability and enhancing lifespan up to $70 \%$, and it is a proposed activator of sirtuin. Further investigation revealed that two structurally similar compounds namely quercetin and piceatannol stimulate SIRT1 activity by five and eightfold, respectively. Both quercetin and piceatannol are polyphenols biochemically (Ferguson, 2001). The biological effects of polyphenols are frequently attributed to antioxidant, metal-ion-chelating and/or free-radical-scavenging activity and there is a possibility that the stimulation of SIRT1 might simply represent the repair of oxidative or metal-ion induced damage to the recombinant protein.

Leptin and adiponectin hormone are found to be beneficially impacted by sirtuin activity. It is noteworthy that these hormones are key regulators of satiety and appetite by regulating activity of 
hypothalamus (Hochberg and Hochberg, 2009). Circulating leptin levels illustrates total visceral adipose tissues. As calorie restriction depletes leptin levels, it in turn enhances adiponectin levels, which have been reported to assert a cardio protective effect (Ziemke and Mantzoros, 2010). Lowering of adipose tissue subsequently lowers the leptin/adiponectin ratio, favoring insulin sensitivity thus maintaining blood glucose level.

Ageing is characterized by significant oxidative damage evoked by free radicals such as superoxide, hydrogen peroxide, peroxynitrite etc. The endogenous network of antioxidant enzymes shields the cell against oxidative stress (Pande and Srinivasan, 2013). Ageing signifies accumulation of damaged proteins, lipids, cells, tissues and organelles in the humans gradually progressing to reduced antioxidant capacity and functionality of these enzymes. Consequently, there is an invariant increased ROS production with old age (Pérez et al., 2009). Since calorie restriction lowers the release of ROS in mitochondria by virtue of sirtuin activation (Sohal and Weindruch, 1996), sirtuin brings about decrease in the detrimental effects of ageing.

Red wine constituents (resveratrol) may positively affect both health and lifespan (Baur et al., 2006) due to activation of SIRT1 (Morselli et al., 2010) and hence there is a possibility of endothelium protection and $\mathrm{NF} \kappa \mathrm{B}$ inhibition which is related to SIRT1 induction. Experimental animals fed diets rich in olive oil phenolics (e.g., hydroxytyrosol) were reported to exhibit decreased oxidative damage markers such as peroxides in several tissues (Bayram et al., 2012; Bajoub et al., 2016), and consumption of olive oil also promoted SIRT1 signaling (Menendez et al., 2013).

Several researches have observed that turmeric and soy contain active principles namely curcumin and isoflavons respectively (Rimbach et al., 2008; Suresh and Srinivasan, 2010). Curcumin has been studied to influence sirtuin activity and other transcription factors (Grabowska et al., 2016) thus explaining its cardioprotective effects in terms of lowering Low Density 
Lipoprotein (LDL) oxidation and inhibition of platelet aggregation. Isoflavons also exert SIRT1 activation effect (Rasbach and Schnellmann, 2008). Seaweed is a rich provider of antioxidant vitamins and polyunsaturated omega 3 fatty acids (Rajapakse and Kim, 2011) which may also exert significant cardioprotective effect by stimulating the activity of sirtuins. Hence there are considerable evidences and scientific studies suggesting towards benefits of consumption of specific diet to induce activation of sirtuins, which in turn offers health benefits and promotes well being.

\section{Conclusion}

Numerous molecules have been recognized as a marders of nutrition. It is generally believed that deacetylases (sirtuins) significantly influence multiple metabolic pathways linked to ageing, inflammation, ischemia, mitochondrial alterations, etc. towards the direction where they promote well-being. A nutritional strategy to restore/improve sirtuin levels, which in turn improves the overall health of the subject, can reveal unexplored powerful horizons for nutritional science and may revolutionize it to a significant extent. But this requires research to substantiate and validate the impact of sirtuins in human subjects. And once it is validated, then nutritionists have the task to develop standard nutritional guidelines to enhance circulating and activity levels of sirtuins in the body. These guidelines will serve to educate common mass as to what and how much to eat so as to improve sirtuin levels in the body, and consequently health. Coupled with this, is the milestone to highlight the safe or optimum or beneficial activity levels of sirtuins in different tissues, thereby identifying current or ongoing health and nutritional status of an individual and devise ways of improving it. There is also the opportunity to develop new and low cost diagnostic methods as bioluminescent methods to undertake quick, economical and convenient testing of sirtuin levels in different body tissues. 
Geolocation- Krasnoyarsk, Siberia, Russia

\section{Acknowledgements}

This work was supported by RFBR [Grant № 16-06-00-439], by Russian Ministry of Education,

Post-Doctoral Program of Project “5-100” [Grant № M 2.2.3], and partially supported by the Russian Science Foundation [Grant № 16-06-14-10115]. 


\section{References}

1. Alp Ikizler, T. (2012). The Use and Misuse of Serum Albumin as a Nutritional Marker in Kidney Disease. Clin. J. Am. Society Nephrol. 7: 1375-1377.

2. Andersen, H. U., Fey, S. J., Larsen, P. M., Nawrocki, A., Hejnaes, K. R., Mandrup-Poulsen, T. and Nerup, J. (1997). Interleukin-1 beta induced changes in the protein expression of rat islets: A computerised database. Electrophoresis 18: 2091-2103.

3. Bajoub, A., Bendini, A., Fernández-gutiÉrrez, A. and Carrasco-Pancorbo, A. (2016). Olive Oil Authentication: A Comparative Analysis of Regulatory Frameworks with Especial Emphasis on Quality and Authenticity Indices, and Recent Analytical Techniques Developed for Their Assessment- A Review. Crit. Rev. Food Sci. Nutr. doi$0.1080 / 10408398.2016 .1225666$.

4. Banh, L. (2006). Serum proteins as markers of nutrition: what are we treating? Prac. Gastroenterol. 46: 46-64.

5. Baur, J.A., Pearson, K.J., Price, N.L., Jamieson, H.A., Lerin, C., Kalra, A., Prabhu, V. V, Allard, J.S., Lopez-Lluch, G., Lewis, K., Pistell, P.J., Poosala, S., Becker, K.G., Boss, O., Gwinn, D., Wang, M., Ramaswamy, S., Fishbein, K.W., Spencer, R.G., Lakatta, E.G., Le Couteur, D., Shaw, R.J., Navas, P., Puigserver, P., Ingram, D.K., de Cabo, R., Sinclair, D.A. (2006). Resveratrol improves health and survival of mice on a high-calorie diet. Nature 444: $337-342$.

6. Bayram, B., Ozcelik B., S Grimm, Roeder, T., Schrader, C., Ernst, I. M., Wagner, A. E., Grune, T., Frank, J. and Rimbach, G. (2012). A diet rich in olive oil phenolics reduces 
oxidative stress in the heart of SAMP8 mice by induction of Nrf2-dependent gene expression. Rejuvenation Res. 15: $71-81$.

7. Beck, F. K. and Rosenthal, T. C. (2002). Prealbumin: A marker for nutritional evaluation. Am. Fam. Physician 65:1575-1578.

8. Bell, E.L., Emerling, B.M., Ricoult, S.J.H. and Guarente, L. (2011). SirT3 suppresses hypoxia inducible factor $1 \alpha$ and tumor growth by inhibiting mitochondrial ROS production. Oncogene 30: 2986-2996.

9. Bordone, L. and Guarente, L. (2005). Calorie restriction, SIRT1 and metabolism: understanding longevity. Nat. Rev. Mol. Cell Biol. 6: 298-305.

10. Borra, M. T., Smith, B. C. and Denu, J. M. (2005). Mechanism of human SIRT1 activation by resveratrol. J. Biol. Chem. 280:17187-17195.

11. Borra, M.T., Denu, J.M. (2004). Quantitative Assays for Characterization of the Sir2 Family of NAD +-Dependent Deacetylases. Methods Enzymol. 376:171-187.

12. Bradbury, C.A., Khanim, F.L., Hayden, R., Bunce, C.M., White, D. A, Drayson, M.T., Craddock, C. and Turner, B.M. (2005). Histone deacetylases in acute myeloid leukaemia show a distinctive pattern of expression that changes selectively in response to deacetylase inhibitors. Leukemia 19: 1751-1759.

13. Brooks, C. L. and Gu, W. (2010). How does SIRT1 affect metabolism, senescence and cancer? Nat. Rev. Cancer 9: 123-128.

14. Budayeva, H.G., Rowland, E.A. and Cristea, I.M. (2016). Intricate Roles of Mammalian Sirtuins in Defense against Viral Pathogens. J. Virol. 90: 5-8.

15. Calabrese, V., Cornelius, C., Leso, V., Trovato-Salinaro, A., Ventimiglia, B., Cavallaro, M., Scuto, M., Rizza, S., Zanoli, L., Neri, S. and Castellino, P. (2012). Oxidative stress, glutathione status, sirtuin and cellular stress response in type 2 diabetes. Biochim. Biophys. Acta 1822: 729-36. 
16. Castro, R.E., Ferreira, D.M.S., Afonso, M.B., Borralho, P.M., MacHado, M. V., CortezPinto, H. and Rodrigues, C.M.P. (2013). MiR-34a/SIRT1/p53 is suppressed by ursodeoxycholic acid in the rat liver and activated by disease severity in human nonalcoholic fatty liver disease. J. Hepatol. 58: 119-125.

17. Chalkiadaki, A. and Guarente, L. (2012). Sirtuins mediate mammalian metabolic responses to nutrient availability. Nat. Rev. Endocrinol. 8: 287-296.

18. Chong, Z.Z. and Maiese, K. (2008). Enhanced tolerance against early and late apoptotic oxidative stress in mammalian neurons through nicotinamidase and sirtuin mediated pathways. Curr. Neurovasc. Res. 5: 159-70.

19. Choudhary, C., Weinert, B.T., Nishida, Y., Verdin, E. and Mann, M. (2014). The growing landscape of lysine acetylation links metabolism and cell signalling. Nat. Rev. Mol. Cell Biol. 15: 536-550.

20. Cohen, D. E., Supinski, A. M., Bonkowski, M. S., Donmez, G. and Guarente, L. P. (2009). Neuronal SIRT1 regulates endocrine and behavioral responses to calorie restriction. Genes Dev. 23: 2812-2817.

21. Combs, G. F., Trumbo, P. R., Mckinley, M. C., Milner, J., Studenski, S., Kimura, T., Watkin, S. M. and Raiten, D. J. (2013). Biomarkers in nutrition: new frontiers in research and application. Ann. NY. Acad. Sci. 1278:1-10.

22. de Roos, B. and McArdle, H. J. (2008). Proteomics as a tool for the modelling of biological processes and biomarker development in nutrition research. Br. J. Nutr. 99: 66-71.

23. Dominy, J. E. Jr, Lee, Y., Gerhart-Hines, Z. and Puigserver, P. (2010). Nutrient-dependent regulation of $\mathrm{PGC}-1$ alpha's acetylation state and metabolic function through the enzymatic activities of Sirt1/GCN5. Biochim. Biophys. Acta 1804: 1676-1683.

24. Don, B.R. and Kaysen, G. (2004). Serum albumin: Relationship to inflammation and nutrition. Semin. Dial. 17: 432-437. 
25. Erion, D.M., Yonemitsu, S., Nie, Y., Nagai, Y., Gillum, M.P., Hsiao, J.J., Iwasaki, T., Stark, R., Weismann, D., Yu, X.X., Murray, S.F., Bhanot, S., Monia, B.P., Horvath, T.L., Gao, Q., Samuel, V.T. and Shulman, G.I. (2009). SirT1 knockdown in liver decreases basal hepatic glucose production and increases hepatic insulin responsiveness in diabetic rats. Proc. Natl. Acad. Sci. U. S. A. 106: 11288-11293.

26. Fan, Y., Ludewig, R. and Scriba, G.K.E. (2009). 9-Fluorenylmethoxycarbonyl-labeled peptides as substrates in a capillary electrophoresis-based assay for sirtuin enzymes. Anal. Biochem. 387: 243-248.

27. Ferguson, L. R. (2001). Role of plant polyphenols in genomic stability. Mutat. Res. 18: 89111.

28. Finley, L.W.S., Carracedo, A., Lee, J., Souza, A., Egia, A., Zhang, J., Teruya-Feldstein, J., Moreira, P.I., Cardoso, S.M., Clish, C.B., Pandolfi, P.P. and Haigis, M.C. (2011). SIRT3 opposes reprogramming of cancer cell metabolism through HIF1alpha destabilization. Cancer Cell 19: 416-428.

29. Ford, E., Voit, R., Liszt, G., Magin, C., Grummt, I. and Guarente, L.(2006). Mammalian Sir2 homolog SIRT7 is an activator of RNA polymerase I transcription. Genes Dev. 20: 10751080.

30. Frye, R. A. (1999). Characterization of five human cDNAs with homology to the yeast SIR2 gene. Biochem. Biophys. Res. Commum. 260: 273-279.

31. Frye, R. A. (2000). Phylogenetic classification of prokaryotic and eukaryotic Sir2-like proteins. Biochem. Biophys. Res. Commun. 273:793-798.

32. Fuchs, D., Winkelmann, I., Johnson, I.T., Mariman, E., Wenzel, U. and Daniel, H. (2005). Proteomics in nutrition research: principles, technologies and applications. Br. J. Nutr. 94: $302-314$. 
33. Gambini, J., Gomez-Cabrera, M.C., Borras, C., Valles, S.L., Lopez-Grueso, R., MartinezBello, V.E., Herranz, D., Pallardo, F. V., Tresguerres, J.A.F., Serrano, M., Viña, J. (2011). Free $[\mathrm{NADH}] /[\mathrm{NAD}+]$ regulates sirtuin expression. Arch. Biochem. Biophys. 512: 24-29.

34. Gertz, M. and Steegborn, C. (2010). Function and regulation of the mitochondrial Sirtuin isoform Sirt5 in Mammalia. Biochim. Biophys. Acta 1804: 1658-1665.

35. Gibson, R. S. (2005). Measuring food composition in individuals In: Principles of Nutritional Assessment, pp. 41-64. Gibson, R. S. Eds., 2nd edition Oxford University Press, New York.

36. Grabowska, W., Suszek, M., Wnuk, M., Lewinska, A., Wasiak, E., Sikora, E. and BielakZmijewska, A. (2016). Curcumin elevates sirtuin level but does not postpone in vitro senescence of human cells building the vasculature. Oncotarget doi: 10.18632/oncotarget 8450.

37. Grbesa, I., Pajares, M.J., Martínez-Terroba, E., Agorreta, J., Mikecin, A.M., Larráyoz, M., Idoate, M.A., Gall-Troselj, K., Pio, R. and Montuenga, L.M. (2015). Expression of sirtuin 1 and 2 is associated with poor prognosis in non-small cell lung cancer patients. PLoS One 10: $1-17$.

38. Greiss, S. and Gartner, A. (2009). Sirtuin/Sir2 phylogeny, evolutionary considerations and structural conservation. Mol. Cells 28: 407-415.

39. Guarente, L. (2006). Sirtuins as potential targets for metabolic syndrome. Nature 444: 868874.

40. Guarente, L. (2014). Linking DNA Damage, NAD+/SIRT1, and Aging. Cell Metab. 20 706707.

41. Gygi, S. P., Corthals, G. L., Zhang, Y., Rochon, Y. and Aebersold, R. (2000). Evaluation of two-dimensional gel electrophoresis based proteome analysis technology. Proc. Natl. Acad. Sci. U. S. A. 97: 9390-9395. 
42. Hafner, A. V., Dai, J., Gomes, A.P., Xiao, C.Y., Palmeira, K.C.M., Rosenzweig, A. and Sinclair, D.A. (2010). Regulation of the mPTP by SIRT3-mediated deacetylation of CypD at lysine 166 suppresses age-related cardiac hypertrophy. Aging (Albany. NY). 2: 914-923.

43. Hagopian, K., Ramsey, J. J. and Weindruch, B. (2009). Caloric restriction counteracts agerelated changes in the activities of sorbitol metabolizing enzymes from mouse liver. Biogerontology 10: 471-479.

44. Haigis, M. C. and Sinclair, D. A. (2010). Mammalian sirtuins: biological insights and disease relevance. Annu. Rev. Pathol. 5: 253-295.

45. Haigis, M.C., Mostoslavsky, R., Haigis, K.M., Fahie, K., Christodoulou, D.C., Murphy, A.J., Valenzuela, D.M., Yancopoulos, G.D., Karow, M., Blander, G., Wolberger, C., Prolla, T.A., Weindruch, R., Alt, F.W. and Guarente, L. (2006). SIRT4 inhibits glutamate dehydrogenase and opposes the effects of calorie restriction in pancreatic beta cells. Cell 126: 941-954.

46. Harikumar, K.B. and Aggarwal, B.B. (2008). Resveratrol: A multitargeted agent for ageassociated chronic diseases. Cell Cycle 7: 1020-1037.

47. Hasegawa, K., Wakino, S., Yoshioka, K., Tatematsu, S., Hara, Y., Minakuchi, H., Washida, N., Tokuyama, H., Hayashi, K. and Itoh, H. (2008). Sirt1 protects against oxidative stressinduced renal tubular cell apoptosis by the bidirectional regulation of catalase expression. Biochem. Biophys. Res. Commun. 372: 51-56.

48. Hauffman, D. M., Grizzle, W. E., Bamman, M. M., Kim, J. S., Eltoum, I. A., Elgavish ,A. and Nagy, T. R. (2007). SIRT1 is significantly elevated in mouse and human prostate cancer. Cancer Res. 67: 6612-6618.

49. Hedrick, V. E., Dietrich, A. M., Estabrooks, P. A., Savla, J., Serrano, E. and Davy, B. M. (2012). Dietary biomarkers: advances, limitations and future directions. Nutr. J. 11:109113. 
50. Heltweg, B., Dequiedt, F., Verdin, E., Jung, M. (2003). Nonisotopic substrate for assaying both human zinc and NAD+-dependent histone deacetylases. Anal. Biochem. 319: 42-48.

51. Herranz, D. and Serrano, M. (2013). Sirt1 : recent lessons from mouse models Nat. Rev. Cancer 10: 819-823.

52. Herranz, D., Muñoz-Martin, M., Cañamero, M., Mulero, F., Martinez-Pastor, B., FernandezCapetillo, O. and Serrano, M. (2010). Sirt1 improves healthy ageing and protects from metabolic syndrome-associated cancer. Nat. Commun. 1: 3.

53. Hirschey, M. D., Shimazu, T., Capra, J. A., Pollard, K. S. and Verdin E. (2011). SIRT1 and SIRT3 deacetylate homologous substrates. Aging 3: 635-642.

54. Hishida, T., Nozaki, Y., Nakachi, Y., Mizuno, Y., Iseki, H., Katano, M., Kamon, M., Hirasaki, M., Nishimoto, M., Okazaki, Y. and Okuda, A. (2012). Sirt1, p53, and p38MAPK are crucial regulators of detrimental phenotypes of embryonic stem cells with Max expression ablation. Stem Cells 30: 1634-1644.

55. Hochberg, I. and Hochberg, Z. (2009). Hypothalamic obesity. Endocrine Dev. 17: 185-196. 56. Hou, X., Xu, S., Maitland-Toolan, K.A., Sato, K., Jiang, B., Ido, Y., Lan, F., Walsh, K., Wierzbicki, M., Verbeuren, T.J., Cohen, R.A. and Zang, M. (2008). SIRT1 regulates hepatocyte lipid metabolism through activating AMP-activated protein kinase. J. Biol. Chem. 283: 20015-20026.

57. Howitz, K. and Bitterman, J., Cohen, H. (2003). Small molecule activators of sirtuins extend Saccharomyces cerevisiae lifespan. Nature 425: 191-196.

58. Hulka, B. S. (1993). Overview of biological markers In: Biological markers in epidemiology, pp. 3-15. Hulka, B. S., Wilcosky, T. C., and Griffin, J. D. Eds., Oxford University Press, New york.

59. Kaaks, R., Riboli, E. and Sinha, R. (1997). Biochemical markers of dietary intake In: Application of Biomarkers in Cancer Epidemiology, pp. 103-126. Toniolo, P., Boffetta, P, 
Shuker, D. E. G., Rothman, N., Hulka, B. and Pearce, N., Eds., IARC Scientific Publications No. 142, International Agency for Research on Cancer, Lyons, France.

60. Kaeberlein, M., McDonagh, T., Heltweg, B., Hixon, J., Westman, E.A., Caldwell, S.D., Napper, A., Curtis, R., DiStefano, P.S., Fields, S., Bedalov, A. and Kennedy, B.K. (2005). Substrate-specific activation of sirtuins by resveratrol. J. Biol. Chem. 280: 17038-17045.

61. Kaidi, A., Weinert, B. T., Choudhary, C. and Jackson, S. P. (2010). Human SIRT6 promotes DNA end resection through CtIP deacetylation. Science 329: 1348-1353.

62. Kanfi, Y., Shalman, R., Peshti, V., Pilosof, S.N., Gozlan, Y.M., Pearson, K.J., Lerrer, B., Moazed, D., Marine, J.C., de Cabo, R. and Cohen, H.Y. (2008). Regulation of SIRT6 protein levels by nutrient availability. FEBS Lett. 582: 543-548.

63. Koyuncu, E., Budayeva, H.G., Miteva, Y. V., Ricci, D.P., Silhavy, T.J., Shenk, T. and Cristea, I.M. (2014). Sirtuins are evolutionarily conserved viral restriction factors. MBio 5, $1-10$.

64. Kuhnle, G. G. C. (2012). Nutritional biomarkers for objective dietary assessment. J. Sci. Food Agric. 92: 1145-1149.

65. Kume, S., Uzu, T., Kashiwagi, A. and Koya, D. (2010). SIRT1, a calorie restriction mimetic, in a new therapeutic approach for type 2 diabetes mellitus and diabetic vascular complications. Endocr. Metab. Immune Disord. Drug Targets 10: 16-24.

66. Kuzuya, M., Izawa, S., Enoki, H., Okada, K. and Iguchi, A. (2007). Is serum albumin a good marker for malnutrition in the physically impaired elderly? Clin. Nutr. 26: 84-90.

67. Laurent, G., de Boer, V.C.J., Finley, L.W.S., Sweeney, M., Lu, H., Schug, T.T., Cen, Y., Jeong, S.M., Li, X., Sauve, A.A. and Haigis, M.C. (2013). SIRT4 Represses Peroxisome Proliferator-Activated Receptor Activity To Suppress Hepatic Fat Oxidation. Mol. Cell. Biol. 33: 4552-4561.

68. Li, X. (2013). SIRT1 and energy metabolism. Acta Biochim. Biophys. Sin. 45: 51-60. 
69. Li, X., Kazgan, N. (2011). Mammalian sirtuins and energy metabolism. Int. J. Biol. Sci.7: 575-587.

70. Li,Y., Xu, R., Zhang, X. M., Li, D. D. and He, Q. Y. (2008). Mechanism of apoptosis induced by SIRT1 deacetylase inhibitors in human breast cancer MCF-7 drug-resistant cells. Yао Хие Хие Вао 43: 1003-1010.

71. Liu, T.F., Vachharajani, V.T., Yoza, B.K. and McCall, C.E. (2012). NAD+ -dependent sirtuin 1 and 6 proteins coordinate a switch from glucose to fatty acid oxidation during the acute inflammatory response. J. Biol. Chem. 287: 25758-25769.

72. Liu, Y., Gerber, R., Wu, J., Tsuruda, T., McCarter, J.D. (2008). High-throughput assays for sirtuin enzymes: A microfluidic mobility shift assay and a bioluminescence assay. Anal. Biochem. 378: 53-59.

73. Lomb, D. J., Laurent, G. and Haigis, M. C. (2010). Sirtuins regulate key aspects of lipid metabolism. Biochim. Biophys. Acta 1804: 1652-1657.

74. Lundby, C. and Olsen, J. V. (2012). Proteomic analysis of lysine acetylation sites in rat tissues reveals organ specificity and subcellular patterns. Cell Rep. 2: 419-431.

75. Luo, J., Nikolaev, A.Y., Imai, S., Chen, D., Su, F., Shiloh, A., Guarente, L. and Gu, W. (2001). Negative control of p53 by Sir2alpha promotes cell survival under stress. Cell 107: 137-48.

76. Maiese, K., Chong, Z. Z., Shang, Y. C. and Hou, J. (2009). A “FOXO” in sight: targeting Foxo proteins from conception to cancer. Med. Res. Rev. 29: 395-418.

77. Mao, Z., Hine, C., Tian, X., Van Meter, M., Au, M., Vaidya, A., Seluanov, A. and Gorbunova, V. (2011). SIRT6 promotes DNA repair under stress by activating PARP1. Science 332: 1443-1446. 
78. Marcotte, P.A., Richardson, P.R., Guo, J., Barrett, L.W., Xu, N., Gunasekera, A. and Glaser, K.B. (2004). Fluorescence assay of SIRT protein deacetylases using an acetylated peptide substrate and a secondary trypsin reaction. Anal. Biochem. 332: 90-99.

79. Martínez-Redondo, P. and Vaquero, A. (2013). The diversity of histone versus nonhistone sirtuin substrates. Genes Cancer 4: 148-63.

80. McDonagh, T., Hixon, J., DiStefano, P. S., Curtis, R. and Napper, A. D. (2005). Microplate filtration assay for nicotinamide release from NAD using a boronic acid resin. Methods 36: $346-350$.

81. Menendez, J.A., Joven, J., Aragonès, G., Barrajón-Catalán, E., Beltrán-Debón, R., BorrásLinares, I., Camps, J., Corominas-Faja, B., Cufí, S., Fernández-Arroyo, S., Garcia-Heredia, A., Hernández-Aguilera, A., Herranz-López, M., Jiménez-Sánchez, C., López-Bonet, E., Lozano-Sánchez, J., Luciano-Mateo, F., Martin-Castillo, B., Martin-Paredero, V., PérezSánchez, A., Oliveras-Ferraros, C., Riera-Borrull, M., Rodríguez-Gallego, E., QuirantesPiné, R., Rull, A., Tomás-Menor, L., Vazquez-Martin, A., Alonso-Villaverde, C., Micol, V., Segura-Carretero, A. (2013). Xenohormetic and anti-aging activity of secoiridoid polyphenols present in extra virgin olive oil: A new family of gerosuppressant agents. Cell Cycle 12: 555-578.

82. Michan, S. and Sinclair, D. (2007). Sirtuins in mammals: insights into their biological function. Biochem. J. 15: 404:1-13.

83. Michishita, E., McCord, R. A., Berber, E., Kioi, M., Padilla-Nash, H., Damian, M., Cheung, P., Kusumoto, R., Kawahara, T. L., Barrett, J. C., Chang, H. Y. Bohr, Y. A. and Ried,T. (2005b) SIRT6 is a histone H3 lysine 9 deacetylase that modulates telomeric chromatin. Nature 452: 492-496.

84. Michishita, E., McCord, R.A., Berber, E., Kioi, M., Padilla-Nash, H., Damian, M., Cheung, P., Kusumoto, R., Kawahara, T.L.A., Barrett, J.C., Chang, H.Y., Bohr, V.A., Ried, T., 
Gozani, O., Chua, K.F. (2008). SIRT6 is a histone H3 lysine 9 deacetylase that modulates telomeric chromatin. Nature 452: 492-496.

85. Michishita, E., Park, J. Y., Burneskis, J. M., Barrett, J. C. and Horikawa, I. (2005a) Evolutionarily conserved and nonconserved cellular localizations and functions of human SIRT proteins. Mol. Biol. Cell 16: 4623-4635.

86. Miroslava, C. and Adrian, S. C. (2014). Role of Histone Deacetylases in Fungal Phytopathogenesis: A Review. Int. J. Modern Botany 4: 48-60.

87. Mischak, H., Allmaier, G., Apweiler, R., Attwood, T., Baumann, M., Benigni, A., Bennett, S.E., Bischoff, R., Bongcam-Rudloff, E., Capasso, G., Coon, J.J., D’Haese, P., Dominiczak, A.F., Dakna, M., Dihazi, H., Ehrich, J.H., Fernandez-Llama, P., Fliser, D., Frokiaer, J., Garin, J., Girolami, M., Hancock, W.S., Haubitz, M., Hochstrasser, D., Holman, R.R., Ioannidis, J.P.A., Jankowski, J., Julian, B.A., Klein, J.B., Kolch, W., Luider, T., Massy, Z., Mattes, W.B., Molina, F., Monsarrat, B., Novak, J., Peter, K., Rossing, P., Sánchez-Carbayo, M., Schanstra, J.P., Semmes, O.J., Spasovski, G., Theodorescu, D., Thongboonkerd, V., Vanholder, R., Veenstra, T.D., Weissinger, E., Yamamoto, T. and Vlahou, A. (2010). Recommendations for biomarker identification and qualification in clinical proteomics. Sci. Transl. Med. 2: 42-45.

88. Morris, B.J. (2013). Seven sirtuins for seven deadly diseases ofaging. Free Radic. Biol. Med. 56: 133-171.

89. Morselli, E., Maiuri, M.C., Markaki, M., Megalou, E., Pasparaki, A., Palikaras, K., Criollo, A., Galluzzi, L., Malik, S. a, Vitale, I., Michaud, M., Madeo, F., Tavernarakis, N. and Kroemer, G. (2010). Caloric restriction and resveratrol promote longevity through the Sirtuin-1-dependent induction of autophagy. Cell Death Dis. 21: 1-11.

90. Muller, P. A. J. and Vousden, K. H. (2013). p53 mutations in cancer. Nat. Cell Biol. 15: 2-8. 
91. Nadtochiy, S.M., Urciuoli, W., Zhang, J., Schafer, X., Munger, J. and Brookes, P.S. (2015). Metabolomic profiling of the heart during acute ischemic preconditioning reveals a role for SIRT1 in rapid cardioprotective metabolic adaptation. J. Mol. Cell. Cardiol. 88: 64-72.

92. Nakagawa, T., Lomb, D.J., Haigis, M.C. and Guarente, L. (2009). SIRT5 Deacetylates Carbamoyl Phosphate Synthetase 1 and Regulates the Urea Cycle. Cell 137: 560-570.

93. Nasrin, N., Wu, X., Fortier, E., Feng, Y., Baré, O.C., Chen, S., Ren, X., Wu, Z., Streeper, R.S. and Bordone, L. (2010). SIRT4 regulates fatty acid oxidation and mitochondrial gene expression in liver and muscle cells. J. Biol. Chem. 285: 31995-32002.

94. Nemoto, S., Fergusson, M. M. and Finkel, T. (2004). Nutrient availability regulates SIRT1 through a fork head dependent pathway. Science 306: 2105-2108.

95. Nie, Y., Erion, D., Yuan, Z., Dietrich, M., Shulman, G., Horvath, T. and Gao, Q. (2009). STAT3 inhibition of gluconeogenesis is downregulated by SirT1. Nat. Cell. Biol. 11:492500.

96. Nikiforov, A., Kulikova, V. and Ziegler, M. (2015). The human NAD metabolome: Functions, metabolism and compartmentalization. Crit. Rev. Biochem. Mol. Biol. 50: 284297.

97. Nogueiras, R., Habegger, K.M., Chaudhary, N., Finan, B., Banks, A.S., Dietrich, M.O., Horvath, T.L., Sinclair, D.A., Pfluger, P.T. and Tschop, M.H. (2012). Sirtuin 1 and sirtuin 3: physiological modulators of metabolism. Physiol. Rev. 92: 1479-1514.

98. North, B.J., Marshall, B.L., Borra, M.T., Denu, J.M. and Verdin, E. (2003). The human Sir2 ortholog, SIRT2, is an NAD+-dependent tubulin deacetylase. Mol. Cell 11: 437-444.

99. Oellerich, M.F. and Potente, M. (2012). FOXOs and sirtuins in vascular growth, maintenance, and aging. Circ. Res. 110: 1238-1251. 
100. Osborne, T. F. and Espenshade, P. J. (2009). Evolutionary conservation and adaptation in the mechanism that regulates SREBP action: What a long, strange tRIP it's been. Genes Dev. 23: 2578-2591.

101. Pagans, S., Pedal, A., North, B.J., Kaehlcke, K., Marshall, B.L., Dorr, A., HetzerEgger, C., Henklein, P., Frye, R., McBurney, M.W., Hruby, H., Jung, M., Verdin, E. and Ott, M. (2005). SIRT1 regulates HIV transcription via Tat deacetylation. PLoS Biol. 3: 02100220.

102. Pallàs, M., Pizarro, J.G., Gutierrez-Cuesta, J., Crespo-Biel, N., Alvira, D., Tajes, M., Yeste-Velasco, M., Folch, J., Canudas, A.M., Sureda, F.X., Ferrer, I. and Camins, A. (2008). Modulation of SIRT1 expression in different neurodegenerative models and human pathologies. Neuroscience 154: 1388-1397.

103. Pallauf, K., Giller, K., Huebbe, P. and Rimbach, G. (2013). Nutrition and healthy ageing: Calorie restriction or polyphenol-rich "mediterrAsian" diet? Oxid. Med. Cell. Longev. 2013: 14-28.

104. Pande, S. and Srinivasan, K. (2012). Potentiation of hypolipidemic and weightreducing influence of dietary tender cluster bean (Cyamopsis tetragonoloba) when combined with capsaicin in high-fat-fed rats. J. Agri. Food Chem. 60: 8155-8162.

105. Pande, S. and Srinivasan, K. (2013). Protective effect of dietary tender cluster beans (Cyamopsis tetragonoloba) in the gastrointestinal tract of experimental rats. Appl. Physiol. Nutr. Metab. 38: 169-176.

106. Pérez, V.I., Bokov, A., Remmen, H. Van, Mele, J., Ran, Q., Ikeno, Y.and Richardson, A. (2009). Is the oxidative stress theory of aging dead? Biochim. Biophys. Acta 1790: $1005-1014$. 
107. Pfluger, P.T., Herranz, D., Velasco-Miguel, S., Serrano, M. and Tschop, M.H. (2008). Sirt1 protects against high-fat diet-induced metabolic damage. Proc. Natl. Acad. Sci. U. S. A. 105: 9793-9798.

108. Picard, F., Kurtev, M., Chung, N., Topark-Ngarm, A., Senawong, T., Machado De Oliveira, R., Leid, M., McBurney, M.W. and Guarente, L. (2004). Sirt1 promotes fat mobilization in white adipocytes by repressing PPAR-gamma. Nature 429: 771-776.

109. Ponugoti, B., Kim, D.H., Xiao, Z., Smith, Z., Miao, J., Zang, M., Wu, S.Y., Chiang, C.M., Veenstra, T.D., Kemper, J.K., (2010). SIRT1 deacetylates and inhibits SREBP-1C activity in regulation of hepatic lipid metabolism. J. Biol. Chem. 285: 33959-33970.

110. Potischman N. (2003). Biologic and Methodologic Issues for Nutritional Biomarkers. J. Nutr. 133: 875S-880S.

111. Priyanka, A., Solanki, V., Parkesh, R. and Thakur, K.G. (2016). Crystal structure of the N-terminal domain of human SIRT7 reveals a three-helical domain architecture. Proteins Struct. Funct. Bioinforma. 1-6. doi:10.1002/prot.25085

112. Prozorovski, T., Schulze-Topphoff, U., Glumm, R., Baumgart, J., Schröter, F., Ninnemann, O., Siegert, E., Bendix, I., Brüstle, O., Nitsch, R., Zipp, F. and Aktas, O. (2008). Sirt1 contributes critically to the redox-dependent fate of neural progenitors. Nat. Cell Biol. 10: $385-94$.

113. Purushotham A, Xu Q, Lu J, Foley JF, Yan X, Kim, D. H. and Kemper, J. K. (2012). Hepatic deletion of SIRT1 decreases hepatocyte nuclear factor 1alpha/farnesoid X receptor signaling and induces formation of cholesterol gallstones in mice. Mol. Cell. Biol. 32: 12261236

114. Purushotham, A., Schug, T. T., Xu, Q., Surapureddi, S., Guo, X. and Li, X. (2009). Hepatocyte-specific deletion of SIRT1 alters fatty acid metabolism and results in hepatic steatosis and inflammation. Cell Metab. 9: 327-38. 
115. Qiu, X., Brown, K., Hirschey, M. D., Verdin, E. and Chen, D. (2010). Calorie restriction reduces oxidative stress by SIRT3-mediated SOD2 activation. Cell. Metab. 1: $662-667$.

116. Rajapakse, N. and Kim, S. K. (2011). Nutritional and digestive health benefits of seaweed. Adv. Food. Nutr. Res. 64:17-28.

117. Rasbach, K.A. and Schnellmann, R.G. (2008). Isoflavones promote mitochondrial biogenesis. J. Pharmacol. Exp. Ther. 325: 536-543.

118. Rauh, D., Fischer, F., Gertz, M., Lakshminarasimhan, M., Bergbrede, T., Aladini, F., Kambach, C., Becker, C.F.W., Zerweck, J., Schutkowski, M. and Steegborn, C. (2013). An acetylome peptide microarray reveals specificities and deacetylation substrates for all human sirtuin isoforms. Nat. Commun. 4: 2327.

119. Ren, J. H., Tao, Y., Zhang, Z. Z., Chen, W.-X., Cai, X. F., Chen, K., Ko, B.C.B., Song, C.-L., Ran, L.K., Li, W. Y., Huang, A. L. and Chen, J. (2014). Sirtuin 1 regulates hepatitis B virus transcription and replication by targeting transcription factor AP-1. J. Virol. 88, 2442-2451.

120. Reny, J. L., Vuagnat, A., Ract, C., Benoit, M. O., Safar, M. and Fagon, J. Y. (2002). Diagnosis and follow-up of infections in intensive care patients: value of C-reactive protein compared with other clinical and biological variables. Crit. Care Med. 30: 529-535.

121. Rimbach, G., Boesch-Saadatmandi, C., Frank, J., Fuchs, D., Wenzel, U., Daniel, H., Hall, W.L. and Weinberg, P.D. (2008). Dietary isoflavones in the prevention of cardiovascular disease - A molecular perspective. Food Chem. Toxicol. 46: 1308-1319.

122. Rodgers, J.T. and Puigserver, P. (2007). Fasting-dependent glucose and lipid metabolic response through hepatic sirtuin 1. Proc. Natl. Acad. Sci. U. S. A. 104: 128611286. 
123. Rodgers, J.T., Lerin, C., Haas, W., Gygi, S.P., Spiegelman, B.M. and Puigserver, P., 2005. Nutrient control of glucose homeostasis through a complex of PGC-1a and SIRT1. Nature 434: 113-118.

124. Rui, L. (2014). Energy metabolism in the liver. Compr. Physiol. 4: 177-197.

125. Sadhukhan, S., Liu, X., Ryu, D., Nelson, O.D., Stupinski, J.A., Li, Z., Chen, W., Zhang, S., Weiss, R.S., Locasale, J.W. and Auwerx, J., Lin, H. (2016). Metabolomicsassisted proteomics identifies succinylation and SIRT5 as important regulators of cardiac function. Proc. Natl. Acad. Sci. 113: 201519858. doi:10.1073/pnas.1519858113

126. Schlicker, C., Gertz, M., Papatheodorou, P., Kachholz, B., Becker, C.F.W. and Steegborn, C. (2008). Substrates and Regulation Mechanisms for the Human Mitochondrial Sirtuins Sirt3 and Sirt5. J. Mol. Biol. 382: 790-801.

127. Schug, T. T., Xu, Q., Gao, H., Peres-da-Silva, A., Draper, D. W., Fessler, M. B., Purushotham, A. and Li, X. (2010). Myeloid deletion of SIRT1 induces inflammatory signaling in response to environmental stress. Mol. Cell Biol. 30: 4712-4721.

128. Schug, T.T. and Li, X. (2011). Sirtuin 1 in lipid metabolism and obesity. Ann. Med. 43: $198-211$.

129. Schuster, S., Roessler, C., Meleshin, M., Zimmermann, P., Simic, Z., Kambach, C., Schiene-Fischer, C., Steegborn, C., Hottiger, M.O. and Schutkowski, M. (2016). A continuous sirtuin activity assay without any coupling to enzymatic or chemical reactions. Sci. Rep. 6: 22643.

130. Schwer, B. and Verdin, E. (2008). Conserved Metabolic Regulatory Functions of Sirtuins. Cell Metab. 7: 104-112.

131. Simó-Mirabet, P., Bermejo-Nogales, A., Calduch-Giner, J.A. and Pérez-Sánchez, J. (2016). Tissue-specific gene expression and fasting regulation of sirtuin family in gilthead sea bream (Sparus aurata). J. Comp. Physiol. B. doi:10.1007/s00360-016-1014-0 
132. Sohal, R.S. and Weindruch, R. (1996). Oxidative stress, caloric restriction, and aging.

Science 273: 59-63.

133. Someya, S., Yu, W., Hallows, W. C., Xu, J., Vann, J. M., Leeuwenburgh, C., Tanokura, M., Denu, J. M. and Prolla, T. A. (2011). Sirt3 mediates reduction of oxidative damage and prevention of age-related hearing loss under caloric restriction. Cell 143: 802812.

134. Spiekerman, A. M. (1995). Nutritional assessment (protein nutrition). Anal. Chem. 67: 29-36.

135. Suresh, D. and Srinivasan, K. (2010). Tissue distribution \& elimination of capsaicin, piperine \& curcumin following oral intake in rats. Indian J. Med. Res. 131: 682-691.

136. Tanno, M., Kuno, A., Yano, T., Miura, T., Hisahara, S., Ishikawa, S., Shimamoto, K. and Horio, Y. (2010). Induction of manganese superoxide dismutase by nuclear translocation and activation of SIRT1 promotes cell survival in chronic heart failure. J. Biol. Chem. 285: $8375-8382$.

137. Tao, R., Coleman, M.C., Pennington, J.D., Ozden, O., Park, S.H., Jiang, H., Kim, H.S., Flynn, C.R., Hill, S., McDonald, W.H., Olivier, A.K., Spitz, D.R. and Gius, D. (2010). Sirt3-Mediated Deacetylation of Evolutionarily Conserved Lysine 122 Regulates MnSOD Activity in Response to Stress. Mol. Cell 40: 893-904.

138. Tarantino, G., Finelli, C., Scopacasa, F., Pasanisi, F., Contaldo, F., Capone, D. and Savastano, S. (2014). Circulating levels of sirtuin 4, a potential marker of oxidative metabolism, related to coronary artery disease in obese patients suffering from nafld, with normal or slightly increased liver enzymes. Oxid. Med. Cell. Longev. 9: 1-10.

139. Trayhurn, P. (2000). Proteomics and nutrition - a science for the first decade of the new millennium. Br. J. Nutr. 83: 1-2. 
140. Vachharajani, V.T., Liu, T., Wang, X., Hoth, J.J., Yoza, B.K. and McCall, C.E. (2016). Sirtuins Link Inflammation and Metabolism. J. Immunol. Res. doi:10.1155/2016/8167273

141. Vakhrusheva, O., Smolka, C., Gajawada, P., Kostin, S., Boettger, T., Kubin, T., Braun, T. and Bober, E. (2008). Sirt7 increases stress resistance of cardiomyocytes and prevents apoptosis and inflammatory cardiomyopathy in mice. Circ. Res. 102: 703-710.

142. Vaquero, A., Scher, M., Lee, D., Erdjument-Bromage, H., Tempst, P. and Reinberg, D. (2004). Human SirT1 interacts with histone H1 and promotes formation of facultative heterochromatin. Mol. Cell 16: 93-105.

143. Walker, A.K., Yang, F., Jiang, K., Ji, J.Y., Watts, J.L., Purushotham, A., Boss, O., Hirsch, M.L., Ribich, S., Smith, J.J., Israelian, K., Westphal, C.H., Rodgers, J.T., Shioda, T., Elson, S.L., Mulligan, P., Najafi-Shoushtari, H., Black, J.C., Thakur, J.K., Kadyk, L.C., Whetstine, J.R., Mostoslavsky, R., Puigserver, P., Li, X., Dyson, N.J., Hart, A.C. and Näär, A.M. (2010). Conserved role of SIRT1 orthologs in fasting-dependent inhibition of the lipid/cholesterol regulator SREBP. Genes Dev. 24: 1403-1417.

144. Wang, F., Nguyen, M., Qin, F.X.F. and Tong, Q. (2007). SIRT2 deacetylates FOXO3a in response to oxidative stress and caloric restriction. Aging Cell 6: 505-514.

145. Wang, T. J., Gona, P., Larson, M. G., Tofler, G. H., Levy, D., Newton-Cheh, C., Jacques, P. F., Rifai, N., Selhub, J., Robins, S. J., Benjamin, E. J., D'Agostino, R. B. and Vasan, R. S. (2006). Multiple biomarkers for the prediction of first major cardiovascular events and death. N. Engl. J. Med. 355: 2631-2639.

146. Wang, W., McReynolds, M.R., Goncalves, J.F., Shu, M., Dhondt, I., Braeckman, B.P., Lange, S.E., Kho, K., Detwiler, A.C., Pacella, M.J. and Hanna-Rose, W. (2015). Comparative metabolomic profiling reveals that dysregulated glycolysis stemming from lack 
of salvage NAD+ biosynthesis impairs reproductive development in Caenorhabditis elegans. J. Biol. Chem. 290: 26163-26179.

147. Wegener, D., Hildmann, C., Riester, D., Schwienhorst, A. (2003). Improved fluorogenic histone deacetylase assay for high-throughput-screening applications. Anal. Biochem. 321: 202-208.

148. Yoshizaki, T., Schenk, S., Imamura, T., Babendure, J.L., Sonoda, N., Bae, E.J., Oh, D.Y., Lu, M., Milne, J.C., Westphal, C., Bandyopadhyay, G. and Olefsky, J.M. (2010). SIRT1 inhibits inflammatory pathways in macrophages and modulates insulin sensitivity. Am. J. Physiol. Endocrinol. Metab. 298: E419-E428.

149. Zhang, S., Wang, X.I. (2013). SIRT1 is a useful biomarker for high-grade dysplasia and carcinoma in barrett's esophagus. Ann. Clin. Lab. Sci. 43: 373-377.

150. Zhang, T. and Kraus, W.L. (2010). SIRT1-dependent regulation of chromatin and transcription: Linking NAD+ metabolism and signaling to the control of cellular functions. Biochim. Biophys. Acta - Proteins Proteomics 1804: 1666-1675.

151. Zhao, K., Chai, X. and Marmorstein, R. (2004). Structure and Substrate Binding Properties of cobB, a Sir2 Homolog Protein Deacetylase from Escherichia coli. J. Mol. Biol. 337: 731-741.

152. Zhao, S., Xu, W., Jiang, W. Yu, W., Lin, Y., Zhang, T., Yao, J., Zhou, L., Zeng, Y., Li, H., Li, Y., Shi, J., An, W., Hancock, S. M., He, F., Qin, L., Chin, J., Yang, P., Chen, X., Lei, Q., Xiong, Y. and Guan, K.L. (2010). Regulation of cellular metabolism by protein lysine acetylation. Science 327:1000-1004.

153. Ziemke, F. and Mantzoros, C.S. (2010). Adiponectin in insulin resistance: Lessons from translational research. Am. J. Clin. Nutr. 91: 258-261. 


\begin{tabular}{|c|c|}
\hline Nutrient/Food & Accepted biomarker \\
\hline Sugar & Urinary sucrose and fructose \\
\hline Calcium & urinary deoxypyridinoline, serum osteocalcin \\
\hline Copper & Serum copper, Serum ceruloplasmin \\
\hline Selenium & Plasma selenium \\
\hline Molybdenum & Urinary sulfate and uric acid \\
\hline Chromium & Impaired glucose tolerance \\
\hline Vitamin A & Serum retinol \\
\hline Whole wheat & Plasma alkylresorcinol \\
\hline Total fat & $\begin{array}{l}\text { RBC concentration of MUFA, PUFA and SFA; plasma } \\
\text { phospholipids and cholesterol esters }\end{array}$ \\
\hline Fatty acids & n-6 and n-3 PUFA in Phospholipids \\
\hline Essential fatty acids & Adipose $\alpha$-linolenic and serum linoleic acid \\
\hline Olive oil & Urinary Tyrosol and hydroxytyrosol phenolic acids \\
\hline Total Proteins & Urinary nitrogen \\
\hline Citrus & Proline betaine \\
\hline Garlic & Urinary S-allyl-mercapturic acid \\
\hline Wine & Urinary or plasma Resveratrol \\
\hline
\end{tabular}

Table 1- The biomarkers for different nutrients and food items 


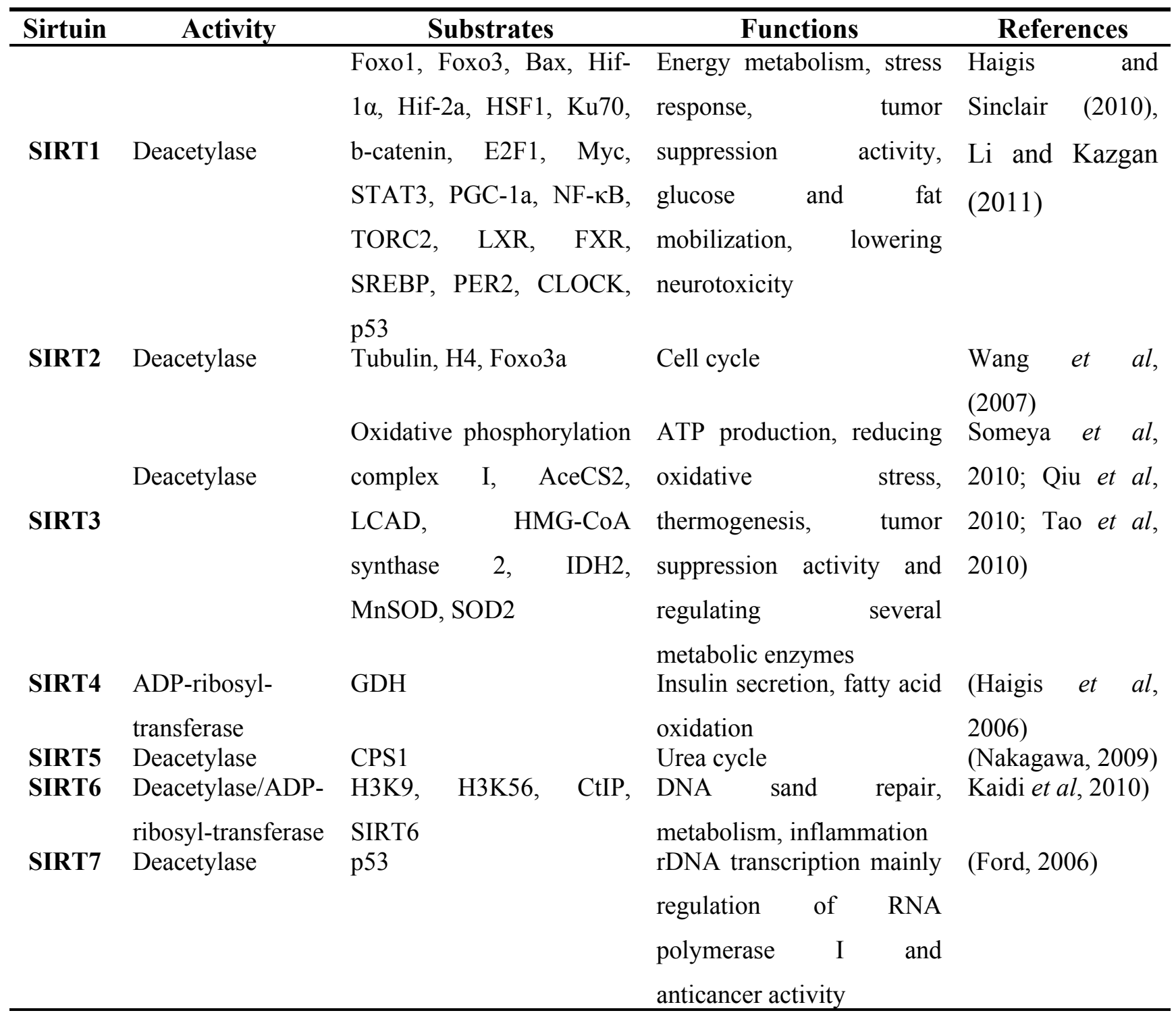

Table 2- Sirtuin metabolism

Abbreviations: p53, tumor suppressor protein 53; Foxo, forkhead box O; Bax, Bc12 associated X protein; Hif, hypoxia-inducible factor; HSF1, heat shock factor 1; STAT3, signal transducer and activator of transcription 3; PGC-1 $\alpha$, peroxisome proliferator-activated receptor gamma coactivator $1 \alpha$; NF- $\kappa \mathrm{B}$, nuclear factor-kappa B; TORC2/CRTC2, a transcriptional coactivator for the 
transcription factor CREB; LXR, liver X receptor; FXR, farnesoid X receptor; SREBP, sterol regulatory element binding protein; PER2, period circadian protein homolog 2; H4, histone 4; AceCS2, acetyl-CoA synthetase 2; LCAD, long-chain acyl CoA dehydrogenase; HMG-CoA synthase 2, 3-hydroxy-3-methylglutaryl CoA synthase 2; IDH2, isocitrate dehydrogenase 2; MnSOD, Mn-superoxide dismutase; SOD2, superoxide dismutase 2; GDH, glutamate dehydrogenase; CPS1, carbamoyl phosphate synthetase 1; CtIP, C-terminal binding protein interacting protein; $\mathrm{H} 3 \mathrm{~K}$ 9, histone 3 acetyl-lysine 9; $\mathrm{H} 3 \mathrm{~K} 56$, histone 3 acetyl-lysine 56; CtIP, Cterminal binding protein interacting protein. 


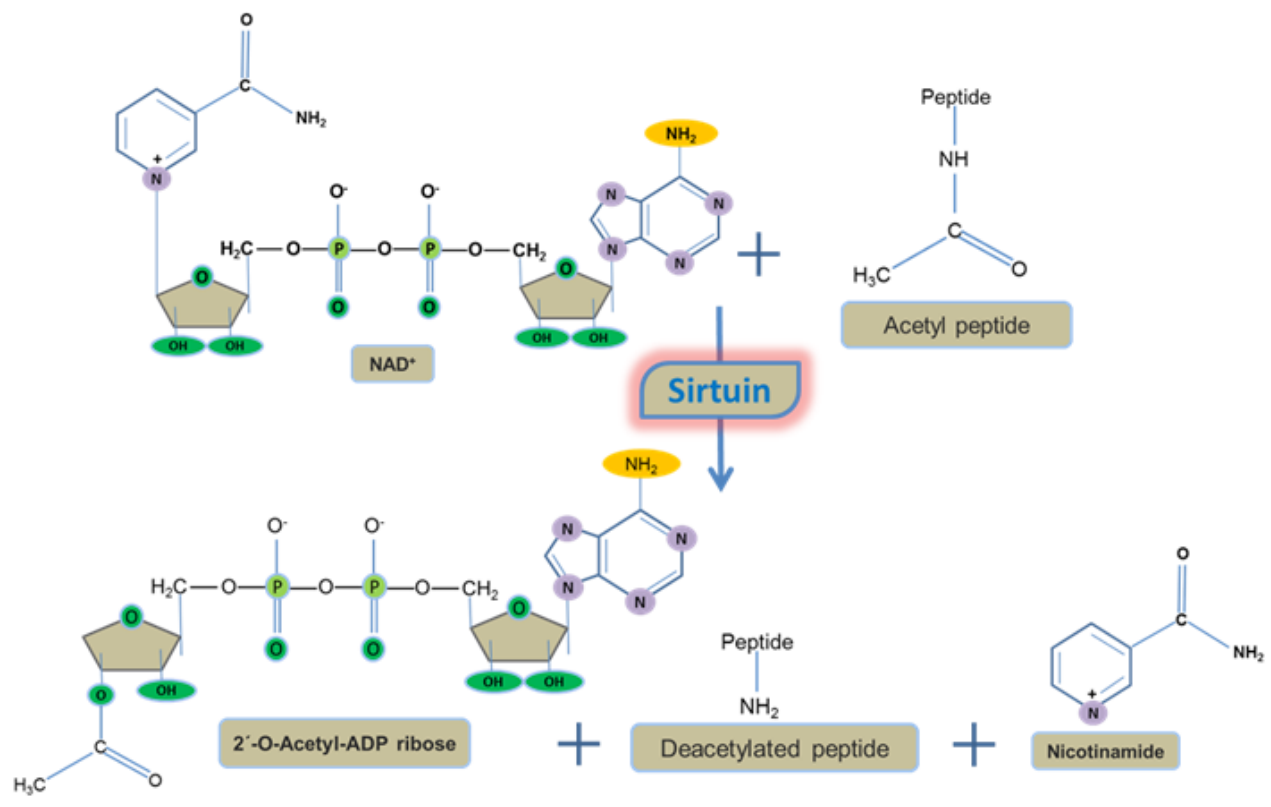

Fig 1- The deacetylation action of sirtuin 


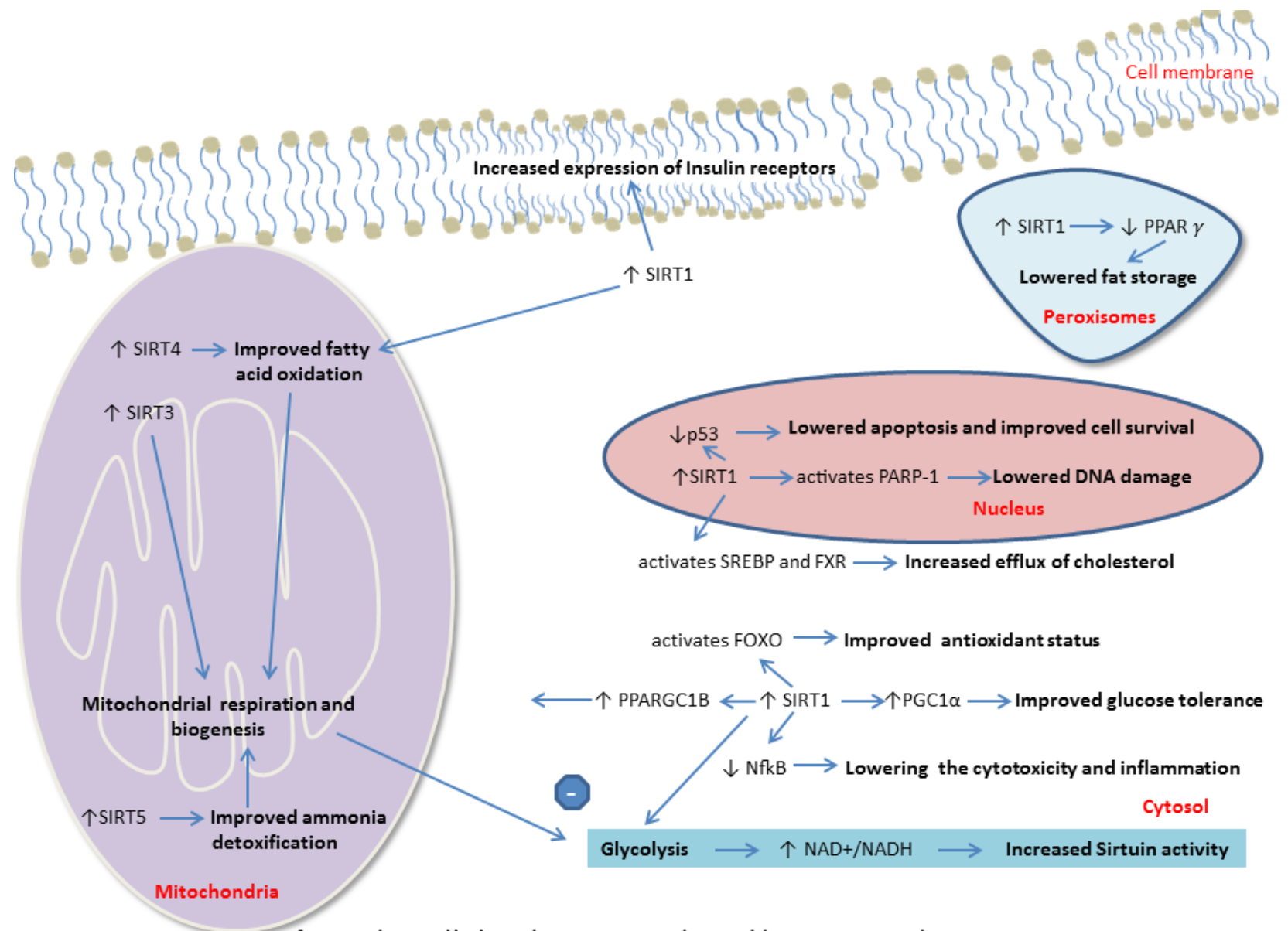

Fig- 2 The cellular changes mediated by improved sirtuin activity 


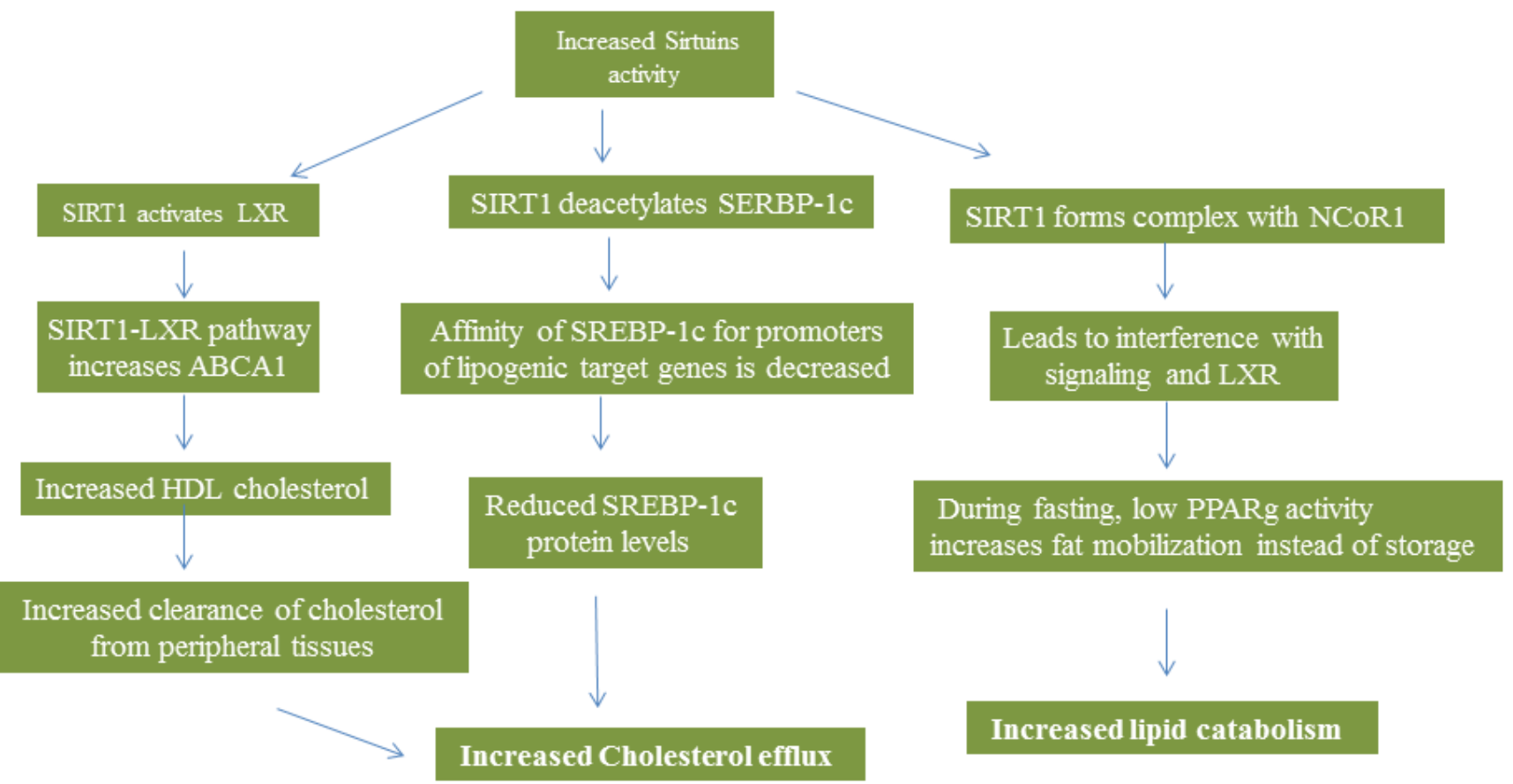

Fig 3- The flowchart depicting series of events leading to lowered cholesterol and lipid levels by sirtuins 